$11-2014$

\title{
Calmodulin enhances ribbon replenishment and shapes filtering of synaptic transmission by cone photoreceptors.
}

\author{
Matthew J. Van Hook \\ University of Nebraska Medical Center, matt.vanhook@unmc.edu \\ Caitlyn M. Parmelee \\ University of Nebraska-Lincoln \\ Minghui Chen \\ University of Nebraska Medical Center, mchen@unmc.edu \\ Karlene M. Cork \\ University of Nebraska Medical Center, kmcork@unmc.edu \\ Carina Curto \\ University of Nebraska-Lincoln
}

See next page for additional authors

Tell us how you used this information in this short survey.

Follow this and additional works at: https://digitalcommons.unmc.edu/com_pen_articles

Part of the Medical Pharmacology Commons, and the Neurosciences Commons

\section{Recommended Citation}

Van Hook, Matthew J.; Parmelee, Caitlyn M.; Chen, Minghui; Cork, Karlene M.; Curto, Carina; and Thoreson, Wallace B., "Calmodulin enhances ribbon replenishment and shapes filtering of synaptic transmission by cone photoreceptors." (2014). Journal Articles: Pharmacology \& Experimental Neuroscience. 5.

https://digitalcommons.unmc.edu/com_pen_articles/5

This Article is brought to you for free and open access by the Pharmacology \& Experimental Neuroscience at DigitalCommons@UNMC. It has been accepted for inclusion in Journal Articles: Pharmacology \& Experimental Neuroscience by an authorized administrator of DigitalCommons@UNMC. For more information, please contact digitalcommons@unmc.edu. 


\section{Authors}

Matthew J. Van Hook, Caitlyn M. Parmelee, Minghui Chen, Karlene M. Cork, Carina Curto, and Wallace B. Thoreson 


\title{
Calmodulin enhances ribbon replenishment and shapes filtering of synaptic transmission by cone photoreceptors
}

\author{
Matthew J. Van Hook, ${ }^{1}$ Caitlyn M. Parmelee, ${ }^{3}$ Minghui Chen, ${ }^{1,2}$ Karlene M. Cork, ${ }^{1,2}$ \\ Carina Curto, ${ }^{3,4}$ and Wallace B. Thoreson ${ }^{1,2}$ \\ ${ }^{1}$ Department of Ophthalmology and Visual Sciences and ${ }^{2}$ Department of Pharmacology and Experimental Neuroscience, \\ University of Nebraska Medical Center, Omaha, NE 68198 \\ ${ }^{3}$ Department of Mathematics, University of Nebraska-Lincoln, Lincoln, NE 68588 \\ ${ }^{4}$ Department of Mathematics, The Pennsylvania State University, University Park, State College, PA 16802
}

\begin{abstract}
At the first synapse in the vertebrate visual pathway, light-evoked changes in photoreceptor membrane potential alter the rate of glutamate release onto second-order retinal neurons. This process depends on the synaptic ribbon, a specialized structure found at various sensory synapses, to provide a supply of primed vesicles for release. Calcium $\left(\mathrm{Ca}^{2+}\right)$ accelerates the replenishment of vesicles at cone ribbon synapses, but the mechanisms underlying this acceleration and its functional implications for vision are unknown. We studied vesicle replenishment using paired whole-cell recordings of cones and postsynaptic neurons in tiger salamander retinas and found that it involves two kinetic mechanisms, the faster of which was diminished by calmodulin (CaM) inhibitors. We developed an analytical model that can be applied to both conventional and ribbon synapses and showed that vesicle resupply is limited by a simple time constant, $\tau=1 /(D \rho \delta s)$, where $D$ is the vesicle diffusion coefficient, $\delta$ is the vesicle diameter, $\rho$ is the vesicle density, and $s$ is the probability of vesicle attachment. The combination of electrophysiological measurements, modeling, and total internal reflection fluorescence microscopy of single synaptic vesicles suggested that CaM speeds replenishment by enhancing vesicle attachment to the ribbon. Using electroretinogram and whole-cell recordings of light responses, we found that enhanced replenishment improves the ability of cone synapses to signal darkness after brief flashes of light and enhances the amplitude of responses to higherfrequency stimuli. By accelerating the resupply of vesicles to the ribbon, CaM extends the temporal range of synaptic transmission, allowing cones to transmit higher-frequency visual information to downstream neurons. Thus, the ability of the visual system to encode time-varying stimuli is shaped by the dynamics of vesicle replenishment at photoreceptor synaptic ribbons.
\end{abstract}

\section{INTRODUCTION}

Visual perception is governed by the nervous system's ability to fashion signals arising from the absorption of photons in the outer segments of rod and cone photoreceptors into a serviceable representation of the surrounding world. Early stages of processing occur at the first synapse in the visual pathway, where graded changes in photoreceptor membrane potential alter the rate of glutamate release onto second-order bipolar and horizontal cells (BCs and HCs, respectively). Thus, the properties of transmission at photoreceptor synapses influence the responses of all downstream neurons, dictating what aspects of rod and cone light responses are available for the visual system to shape into perception.

The synaptic signaling capabilities of photoreceptors depend on the synaptic ribbon, a proteinaceous structure responsible for providing a supply of glutamate-laden

Correspondence to Matthew J. Van Hook: matt.vanhook@unmc.edu

Abbreviations used in this paper: BC, bipolar cell; CaM, calmodulin; EPSC, excitatory postsynaptic current; ERG, electroretinogram; HC, horizontal cell; IRP, immediately releasable pool; MLCK, myosin light chain kinase; PPR, paired pulse ratio; RBC, rod BC; TIRFM, total internal reflection fluorescence microscopy.

primed vesicles for release at the presynaptic membrane (Heidelberger et al., 2005; Snellman et al., 2011). Recent studies have shown that the interplay of vesicle release and replenishment at the ribbon are important in encoding luminance and contrast by cones (Jackman et al., 2009; Babai et al., 2010) and rod BCs (RBCs; Oesch and Diamond, 2011; Ke et al., 2014).

The dynamics of release and replenishment at photoreceptor synapses might also be an important factor in encoding and transmitting the timing of light responses. Rod and cone synapses function as band-pass filters (Armstrong-Gold and Rieke, 2003; Burkhardt et al., 2007). Although several presynaptic factors, including gap-junctional coupling, voltage-gated conductances, and synaptic release kinetics, likely contribute to this (ArmstrongGold and Rieke, 2003; Zhang and Wu, 2005; Burkhardt et al., 2007; Barrow and Wu, 2009), the role of synaptic vesicle replenishment has not yet been explored.

(C) 2014 Van Hook et al. This article is distributed under the terms of an AttributionNoncommercial-Share Alike-No Mirror Sites license for the first six months after the publication date (see http://www.rupress.org/terms). After six months it is available under a Creative Commons License (Attribution-Noncommercial-Share Alike 3.0 Unported license, as described at http://creativecommons.org/licenses/by-nc-sa/3.0/).

The Rockefeller University Press $\$ 30.00$ 
$\mathrm{Ca}^{2+}$ accelerates vesicle replenishment at a variety of conventional (Dittman and Regehr, 1998; Stevens and Wesseling, 1998; Wang and Kaczmarek, 1998; Sakaba and Neher, 2001; Kuromi and Kidokoro, 2002) and ribbon (Mennerick and Matthews, 1996; Gomis et al., 1999; Singer and Diamond, 2006; Johnson et al., 2008; Babai et al., 2010; Cho et al., 2011) synapses. At the calyx of Held, $\mathrm{Ca}^{2+}$ acts through the $\mathrm{Ca}^{2+}$ signaling protein calmodulin $(\mathrm{CaM})$ to enhance a fast mode of replenishment (Sakaba and Neher, 2001). The mechanisms underlying $\mathrm{Ca}^{2+}$ dependent acceleration of replenishment at ribbon synapses are unknown. CaM offers an obvious candidate mechanism. Although $\mathrm{Ca}^{2+}$ is known to accelerate replenishment at ribbon synapses, the fraction of the releasable pool emptied in BCs and cones by a depolarizing step remained unchanged throughout a maintained depolarizing step, suggesting that replenishment rate is determined solely by the number of available attachment sites (i.e., occupancy state) on the ribbon and does not involve acceleration by $\mathrm{Ca}^{2+}$ (Babai et al., 2010; Oesch and Diamond, 2011).

These findings lead us to ask two questions. (1) Where does $\mathrm{Ca}^{2+}$ act to accelerate replenishment and is $\mathrm{CaM}$ involved? (2) What role does $\mathrm{Ca}^{2+}$-dependent acceleration play in shaping the temporal response properties of cone synaptic transmission? To answer these questions, we combined electrophysiological and optical measurements with an analytical model of vesicle resupply. This model can be applied to both ribbon and conventional synapses to predict a fundamental time constant limiting vesicle replenishment. We found that $\mathrm{Ca}^{2+}$ and $\mathrm{CaM}$ enhance a fast kinetic component of replenishment at cone synapses. However, unlike the calyx of Held where CaM appears to act via Munc13 to enhance vesicle priming at the membrane (Z. Chen et al., 2013; Lipstein et al., 2013), our results suggest that CaM acts on ribbon-associated proteins to increase the likelihood that vesicles attach to ribbons. Furthermore, by disrupting CaM, we found that $\mathrm{Ca}^{2+}$-dependent replenishment accelerates replenishment in cones over short time intervals and thus plays an important role in setting the high-frequency fall off of cone synaptic transmission. These results indicate that the ability of the visual system to encode timevarying stimuli is shaped by the dynamics of vesicle replenishment at photoreceptor synaptic ribbons.

\section{MATERIALS AND METHODS}

\section{Animals}

Experiments were performed using retinas of aquatic tiger salamanders (Ambystoma tigrinum; Charles Sullivan) of both sexes (18-25 cm in length). Care and handling protocols were approved by the Institutional Animal Care and Use Committee at the University of Nebraska Medical Center. Animals were housed on a 12-h light/dark cycle at $4-8^{\circ} \mathrm{C}$. 1-2 $\mathrm{h}$ after the beginning of the dark cycle, animals were decapitated, quickly pithed, and enucleated.

\section{Retinal slices}

Details of the retinal slice preparation and whole-cell recording are described elsewhere (Van Hook and Thoreson, 2013). In brief, the anterior segment of the eye, including the lens, was removed, and the resulting eyecup was cut into quarters. One or two pieces were placed vitreal side down on a nitrocellulose membrane $(5 \times 10 \mathrm{~mm}$; type AAWP, $0.8 \mu \mathrm{m}$ pores; EMD Millipore). The filter paper with pieces of eyecup was submerged in cold amphibian saline, and the sclera was gently peeled away, leaving the retina adhering to the membrane. The retina was then cut into 125 - $\mu \mathrm{m}$ slices using a razor blade tissue slicer (Stoelting Co.) and slices were rotated $90^{\circ}$ to view the retinal layers and anchored in the recording chamber by embedding the ends of the filter paper in vacuum grease. Slices were prepared under fiber optic illumination (white light, $\sim 1,000$ lux).

\section{Patch-clamp electrophysiology}

Recordings were performed on an upright fixed-stage microscope (E600FN; Nikon) equipped with a $60 \times$ water-immersion objective. Slices were superfused at $\sim 1 \mathrm{ml} / \mathrm{min}$ with an oxygenated amphibian saline solution containing the following $(\mathrm{mM})$ : $116 \mathrm{NaCl}, 2.5 \mathrm{KCl}, 1.8 \mathrm{CaCl}_{2}, 0.5 \mathrm{MgCl}_{2}, 5$ glucose, and 10 HEPES. The $\mathrm{pH}$ was adjusted to 7.8 with $\mathrm{NaOH}$. Osmolarity was measured with a vapor pressure osmometer (Wescor) and adjusted to 240-245 mOsm. Unless otherwise specified, reagents were obtained from Sigma-Aldrich.

Patch pipettes were pulled from borosilicate glass (1.2 mm OD, $0.9 \mathrm{~mm}$ ID, with an internal filament; World Precision Instruments) using a PC-10 vertical pipette puller (Narishige) and had resistances of 15-20 M 2 . The standard pipette solution for cones contained $(\mathrm{mM}) 90 \mathrm{CsOH}, 50$ gluconic acid, 40 glutamic acid, 10 TEA-Cl, $3.5 \mathrm{NaCl}, 1 \mathrm{CaCl}_{2}, 1 \mathrm{MgCl}_{2}, 9.4$ ATP-Mg, 0.5 GTP-Na, 10 HEPES, and 5 EGTA. The $\mathrm{pH}$ was adjusted to 7.2 and the osmolarity was adjusted to 235-240 with CsOH. For recordings from HCs and BCs, the pipette solution was the same except that the glutamic acid was replaced with $40 \mathrm{mM}$ gluconic acid. In some experiments, indicated in the Results, we replaced $5 \mathrm{mM}$ EGTA with $1 \mathrm{mM}$ BAPTA. The liquid junction potential was measured as $-9 \mathrm{mV}$ and was not corrected.

Whole-cell patch-clamp recordings were made from HCs, BCs, and cones under white light illumination. Cells were targeted based on morphology and soma position, and identity of HCs and BCs was confirmed by physiological criteria and their response to a flash of light. Cones were voltage clamped at $-70 \mathrm{mV}$, and HCs and BCs were voltage clamped at $-60 \mathrm{mV}$ with a Multiclamp $700 \mathrm{~A}$ amplifier. For paired recordings, we targeted cones and postsynaptic neurons positioned adjacent to one another in the slice. Signals were digitized at $10 \mathrm{kHz}$ with a Digidata 1322A A:D/D:A interface and low pass filtered with a cutoff of $2 \mathrm{kHz}$. Recordings were excluded if the cone access resistance $(\mathrm{Ra})$ exceeded $60 \mathrm{M} \Omega$ or changed dramatically over the course of the recording or if the cone holding current was $>200 \mathrm{pA}$. Mean values for Ra, membrane capacitance, and membrane resistance in cones were $44 \pm 0.7 \mathrm{M} \Omega$, $75 \pm 2 \mathrm{pF}$, and $293 \pm 10 \mathrm{M} \Omega$, respectively $(n=83)$.

For measurements of cone membrane potential, we made perforated patch current clamp recordings by including $200 \mu \mathrm{M}$ amphotericin-B (prepared from a $200 \mathrm{mM}$ stock solution made in DMSO) in the pipette solution. After establishing a gigaohm seal, we waited several minutes for the development of small wholecell capacitance transients (usually $<5 \mathrm{~min}$ ). Perforated patch recordings were terminated if we were unable to record a membrane voltage close to the expected cone dark potential (approximately $-40 \mathrm{mV}$ ).

To measure postsynaptic glutamate receptor currents independently of release from photoreceptors, 4-methoxy-7-nitroindolinyl-caged L-glutamate (MNI glutamate; Tocris Bioscience) was bath-applied (1 mM) and photolyzed with 1-ms flashes of UV light 
from a xenon arc flash lamp (Rapp OptoElectronic) delivered through a quartz fiber optic mounted to the epifluorescence port of the microscope and directed onto the slice through the objective lens.

$\mathrm{Ca}^{2+}$ currents $\left(I_{\mathrm{Ca}}\right)$ evoked by a $100-\mathrm{ms}$ depolarizing step were recorded with a $\mathrm{P} / 8$ leak subtraction protocol. For comparison between conditions, the charge of the $I_{\mathrm{Ca}}\left(Q_{\mathrm{Ca}}\right)$, measured over $100 \mathrm{~ms}$, was normalized to the whole-cell membrane capacitance determined with a single exponential fit to the whole-cell capacitance transient. The voltage dependence of $Q_{\mathrm{Ca}}$ was determined by fitting with a Boltzmann sigmoidal function.

The ratios of the amplitudes of excitatory postsynaptic currents (EPSCs) evoked in response to pairs of presynaptic depolarizing pulses (100-ms steps to $-10 \mathrm{mV}$ ) were measured with interstimulus intervals ranging from $200 \mathrm{~ms}$ to $60 \mathrm{~s}$. We also measured replenishment rate with trains of depolarizing pulses $(25 \mathrm{~ms}$ pulses applied at $13.3 \mathrm{~Hz}$ ). In these experiments, replenishment rate was measured as the slope of a straight line fit to the cumulative charge transfer of the postsynaptic response. We adjusted the baseline to remove contributions from background synaptic inputs.

HC mEPSCs were detected and their amplitude was measured using MiniAnalysis 6.0.7 (Synaptosoft). After automatic detection by the software, each event was also inspected by eye. If necessary, the preceding baseline period was adjusted in length to improve the amplitude measurement. Double peaks were analyzed using an algorithm within Synaptosoft that extrapolates the exponential decay of the first peak.

\section{Light stimuli}

Sinusoidal light stimuli were generated by modulating the voltage across a white light LED with a function generator (BK Precision). Analysis of power spectra showed that there were small harmonic contributions to the light output of the LED (measured with a photodiode) but that their power was attenuated by $>50$-fold relative to the power at the fundamental frequency. White light flash stimuli from a halogen lamp were directed onto the slices from below through the microscope condenser, filtered to remove infrared wavelengths, and attenuated with a neutral density filter. To ensure that rods were strongly light adapted, bright white light illumination was used during slice preparation and establishment of whole-cell recordings. In some experiments, we applied a strong rod-adapting background $\left(\lambda=480 \mathrm{~nm} ; 2.4 \times 10^{4}\right.$ photons $\left.\mu \mathrm{m}^{-2} \mathrm{~s}^{-1}\right)$ during the recording. However, responses were not different in the presence or absence of this rod-adapting light, suggesting that responses were principally cone driven even in the absence of a rodadapting background, so we pooled these data.

$\mathrm{HC}$ and Off $\mathrm{BC}$ light responses were measured as the charge $(Q)$ of the membrane current integrated for $500 \mathrm{~ms}$ from the end of the light flash. The amplitude of responses to sinusoidal light stimuli was measured by fitting traces with a sine-wave function in pClamp. The frequency of $50 \%$ attenuation of the response amplitude $\left(f_{50}\right)$ was measured by fitting the frequency-response plots with a Boltzmann sigmoid.

Total internal reflection fluorescence microscopy (TIRFM) We used TIRFM to monitor single vesicle fusion events in isolated cones using techniques described previously (M. Chen et al., 2013). In brief, retinas were incubated in amphibian saline containing $500 \mu \mathrm{g} / \mathrm{ml}$ of a $10 \mathrm{kD}$-conjugated, $\mathrm{pH}$-sensitive form of rhodamine (pHrodo; Invitrogen) for $3 \mathrm{~min}$ in darkness at $20^{\circ} \mathrm{C}$. This brief incubation period loads only $1-3 \%$ of the synaptic vesicles, allowing us to image individual vesicles. After loading, retinas were digested by incubation with $30 \mathrm{U} / \mathrm{ml}$ papain (Worthington Biochemical Corporation) plus $0.2 \mathrm{mg} / \mathrm{ml}$ cysteine in $\mathrm{Ca}^{2+}$-free amphibian saline for $35 \mathrm{~min}$ at $20^{\circ} \mathrm{C}$. The tissue was then washed in $\mathrm{Ca}^{2+}$-free amphibian saline containing $1 \%$ bovine serum albumin and $1 \mathrm{mg} / \mathrm{ml}$ DNase (Worthington Biochemical
Corporation) and triturated using a fire-polished Pasteur pipette. The resulting cell suspension was transferred onto 1.78 refractive index glass coverslips (Olympus) coated with Cell-Tak (BD), and cells were allowed to adhere for $30 \mathrm{~min}$, after which they were transferred to the microscope stage and superfused with oxygenated amphibian saline. A solid-state 561-nm wavelength laser (Melles Griot) was used to illuminate $\mathrm{pHrodo-loaded} \mathrm{vesicles.} \mathrm{The} \mathrm{laser} \mathrm{was}$ focused off-axis onto the back focal plane of a 1.65-NA objective (Apo 100× oil; Olympus). After leaving the objective, light traveled through a high refractive index (1.78) immersion fluid (Cargille Laboratories) and entered the coverslip, undergoing total internal reflection at the interface between the glass and lower refractive index of the cell membrane and overlying aqueous medium. The evanescent wave propagated at this interface had a length constant of $64 \mathrm{~nm}$ (M. Chen et al., 2013). Individual cones were depolarized with a puff of $50 \mathrm{mM} \mathrm{KCl}$ (1-s duration) delivered with a Toohey Spritzer pressure system (Toohey Company). Alternatively, some cells were targeted for whole-cell recording and depolarized with a step to $-10 \mathrm{mV}$ from a holding potential of $-70 \mathrm{mV}$ for 50-500 ms using an A-M Systems model 2400 patch-clamp amplifier. Images were acquired at $41 \mathrm{~ms} /$ frame. The membrane dwell times for individual vesicles were measured from the number of frames during which pHrodo fluorescence intensity remained $\geq 90 \%$ of the peak intensity. We restricted analysis to events that occurred in the synaptic terminal (located using bright field images), and fusion events were defined as disappearance events in which pHrodo fluorescence intensity declined by $>60 \%$ within $83 \mathrm{~ms}$ (M. Chen et al., 2013).

\section{Capacitance recordings}

Whole-cell capacitance recordings were performed using the phase-tracking circuitry of the lock-in amplifier integrated into the Optopatch patch-clamp amplifier (Cairn Research; Johnson et al., 2002). As described previously (Van Hook and Thoreson, 2012), the holding potential was varied sinusoidally at $500 \mathrm{~Hz}, 30 \mathrm{mV}$ peak-to-peak around a holding potential of $-70 \mathrm{mV}$. We blanked output from the phase lock amplifier for $3 \mathrm{~ms}$ after the end of the step and began measurements $30 \mathrm{~ms}$ later to avoid influence of gating charges and allow time for the phase angle feedback circuitry to settle. Amplifier output of membrane current, membrane capacitance, and series resistance were digitized with a Digidata 1322A (Axon/Molecular Devices) and acquired with pClamp9.2 software (Axon/Molecular Devices). Signals were lowpass filtered with a cutoff of $2 \mathrm{kHz}$ for membrane current and 100 $\mathrm{Hz}$ for capacitance and series resistance. Recordings with appreciable poststimulus changes in series resistance were excluded. Patch pipettes for capacitance recordings were coated with dental wax to reduce stray capacitance. The time course of endocytosis was measured as the time from the end of the depolarizing step to $50 \%$ decay of the capacitance signal $\left(t_{50}\right)$.

\section{Drugs/pharmacology}

To partially antagonize $I_{\mathrm{Ca}}$, we bath-applied a subsaturating concentration of the dihydropyridine nifedipine $(3 \mu \mathrm{M})$, which was diluted to its working concentration in amphibian saline from a $10,000 \times$ stock made in DMSO. Calmidazolium (Tocris Bioscience) was diluted to its working concentration $(20 \mu \mathrm{M})$ immediately before use in amphibian saline from a $1,000 \times$ stock made in DMSO. The myosin light chain kinase (MLCK) peptide and MLCKcontrol peptide (EMD Millipore) were dissolved to the working concentration $(20 \mu \mathrm{M})$ in the pipette solution and introduced through the cone patch pipette. Their sequences are as follows: MLCK, RRKWQKTGHAVRAIGRL; MLCK-control, RRKEQKTGHAVRAIGRE. When introducing peptides through the patch pipette, we waited $>5$ min after breaking in before beginning data collection to allow time for the peptides to reach the terminal. 


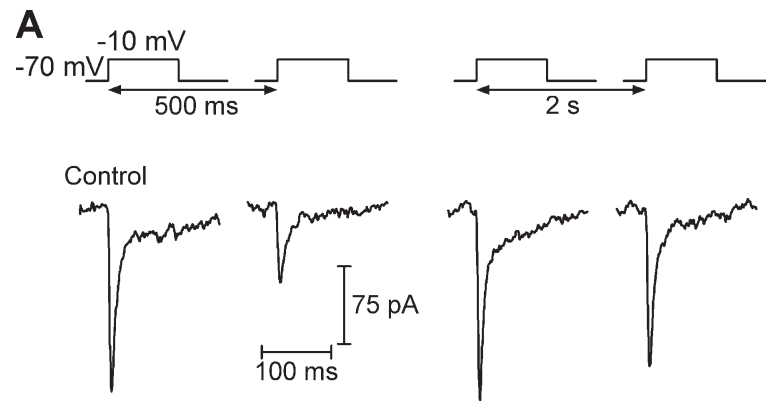

B
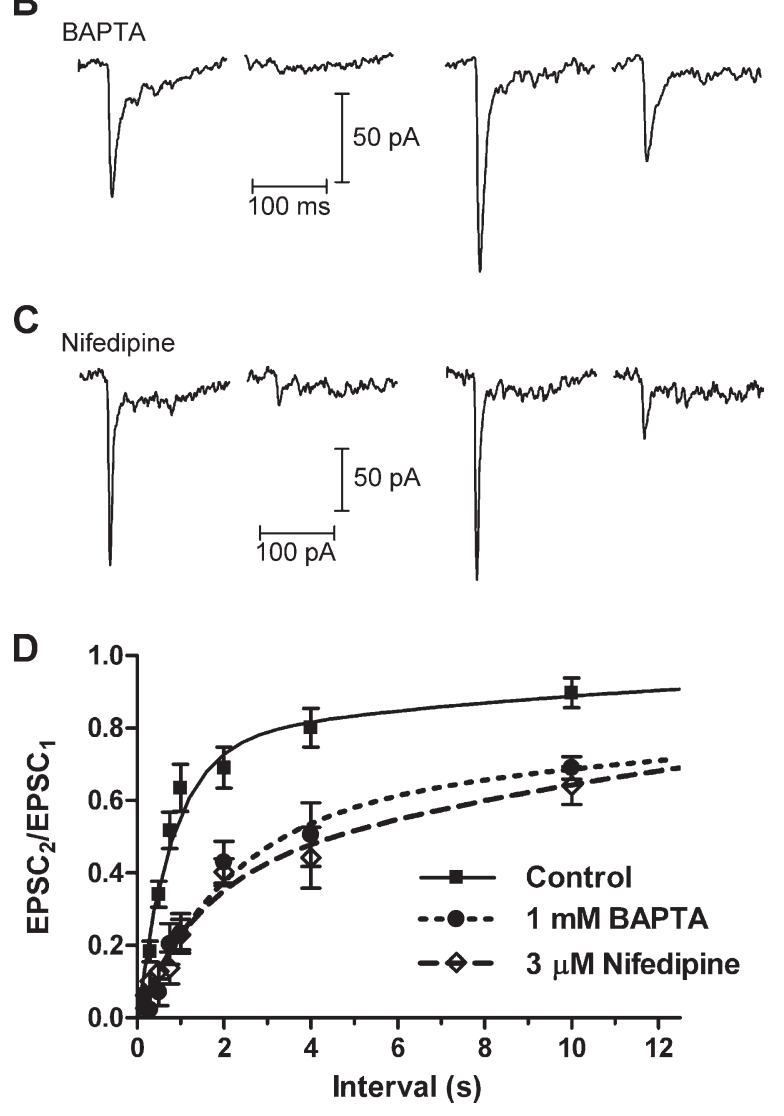

Figure 1. Recovery from synaptic depression depends on $\mathrm{Ca}^{2+}$. (A) In paired recordings, a 100-ms depolarization of a cone to $-10 \mathrm{mV}$ from a holding potential of $-70 \mathrm{mV}$ evoked an EPSC in an HC. A second depolarization applied after a short interval $(500 \mathrm{~ms})$ evoked a smaller EPSC. The amplitude of the second EPSC largely recovered after a 2-s interval. (B) When the cone pipette solution contained $1 \mathrm{mM}$ BAPTA, which restricts the spread of intracellular $\left[\mathrm{Ca}^{2+}\right]$ away from $\mathrm{Ca}^{2+}$ channels, the amplitude of the second EPSC was reduced relative to control conditions. (C) Subsaturating inhibition of L-type $\mathrm{Ca}^{2+}$ channels with bath-applied nifedipine $(3 \mu \mathrm{M})$, which reduced $\mathrm{Ca}^{2+}$ influx by $\sim 40 \%$, also inhibited recovery from paired pulse depression, similar to BAPTA. (D) Group data showing the recovery from synaptic depression. As the interval between pulses increased, the PPR of the EPSCs $\left(\mathrm{EPSC}_{2} / \mathrm{EPSC}_{1}\right)$ could be fit with two exponentials. Under control conditions, the fast time constant $\left(\tau_{\text {fast }}\right)$ was $816 \mathrm{~ms}(76 \%)$ and the slow time constant $\left(\tau_{\text {slow }}\right)$ was $12.9 \mathrm{~s}$. In the presence of $1 \mathrm{mM}$ BAPTA or $3 \mu \mathrm{M}$ nifedipine, recovery from synaptic depression was slowed; with BAPTA, $\tau_{\text {fast }}=$ $2.1 \mathrm{~s}(56 \%)$ and $\tau_{\text {slow }}=28.8 \mathrm{~s}$. In the presence of nifedipine, $\tau_{\text {fast }}=1.4 \mathrm{~s}$ $(37 \%)$ and $\tau_{\text {slow }}=17.6 \mathrm{~s}$. Mean \pm SEM is shown.
Intraretinal electroretinogram (ERG)

Intraretinal ERG recordings were made from salamander eyecups superfused at $\sim 1 \mathrm{ml} / \mathrm{min}$. In brief, the eye was cut along the ora serrata, and the lens and vitreous were removed. The remaining eyecup was positioned on cotton that was moistened with amphibian saline and in contact with an $\mathrm{Ag} / \mathrm{AgCl}$ pellet reference electrode and anchored with a piece of Kimwipe. ERGs were recorded by advancing a patch pipette filled with amphibian saline through the retina until a large negative b-wave and positive a-wave could be recorded in response to a flash, indicating that the pipette was positioned proximal to the outer limiting membrane. White light stimuli were directed onto the eyecup through a fiber optic positioned above the preparation. In flash-duration experiments, the d-wave was isolated by applying the metabotropic glutamate receptor agonist L-AP4 $(10 \mu \mathrm{M})$, which blocks the b-wave (Massey et al., 1983). For analysis, the d-wave peak amplitude was measured from the PIII component immediately before light offset. Photoreceptor responses were measured from baseline either as the fast peak of the PIII wave (in the presence of L-AP4) or as the a-wave (in the absence of L-AP4). ERG signals were recorded with a Multiclamp 700A amplifier and digitized with a Digidata $1322 \mathrm{~A}$ at $10 \mathrm{kHz}$ and were low-pass filtered with a cutoff frequency of 100-200 Hz.

Analysis of all electrophysiology data was performed using pClamp 10 (Axon/Molecular Devices), Excel (Microsoft), and Prism 4.0 software (GraphPad Software). Unless otherwise noted, data are reported as mean \pm SEM and were considered significant for values of $\mathrm{P}<0.05$, as determined with a two-tailed independent Student's $t$ test.

\section{Online supplemental material}

This supplemental material contains four figures and their legends. Fig. S1 shows that calmidazolium had no effect on mEPSC amplitude. Fig. S2 illustrates TIRFM data showing that the membrane dwell time of individual vesicles is too short to be rate limiting for the replenishment process. In Fig. S3, we show the lack of an effect of the CaM inhibitor calmidazolium on the light responses of individual cones, whereas in Fig. S4 we show that there was no effect on the population light response measured with the ERG awave. Online supplemental material is available at http://www.jgp .org/cgi/content/full/jgp.201411229/DC1.

\section{RESULTS}

\section{$\mathrm{Ca}^{2+} / \mathrm{CaM}$ quicken recovery from synaptic depression}

Previous work has used trains of depolarizing pulses to show that replenishment at the cone ribbon synapse is accelerated by $\mathrm{Ca}^{2+}$ (Babai et al., 2010). To explore the mechanisms underlying this effect, we recorded EPSCs in HCs evoked by stimulating cones with pairs of depolarizing steps ( -70 to $-10 \mathrm{mV}, 100 \mathrm{~ms}$; Fig. 1). Release from cones appears to occur only at ribbons (Snellman et al., 2011), and this stimulus releases the entire immediately releasable pool (IRP) of vesicles at the base of the ribbon with $100 \%$ release probability (Bartoletti et al., 2010). Depression at the photoreceptor synapse is mediated principally by depletion of vesicles from the releasable pool rather than by desensitization of postsynaptic AMPA receptors (Rabl et al., 2006). Thus, varying the interval between the pulses from $200 \mathrm{~ms}$ to $60 \mathrm{~s}$ allowed us to monitor the time course of replenishment of vesicles into the IRP, measured as the paired pulse ratio (PPR) of 
the two EPSCs $\left(\mathrm{EPSC}_{2} / \mathrm{EPSC}_{1}\right)$. We found that the time course of replenishment could be fit with two exponential functions with $\tau_{\text {fast }}=815 \mathrm{~ms}(76 \%)$ and $\tau_{\text {slow }}=13.0 \mathrm{~s}$, suggesting that the ribbon is replenished by two kinetic mechanisms, one fast and one slower (Fig. 1 and Table 1). At an interval of $2 \mathrm{~s}$, the PPR was $0.69 \pm 0.06(n=10)$.

We used two approaches to assess the effects of $\mathrm{Ca}^{2+}$ on these two kinetic components of recovery at the cone synapse (Fig. 1, B-D). In the first, we replaced $5 \mathrm{mM}$ EGTA in our control pipette solution with $1 \mathrm{mM}$ of the fast chelator BAPTA (Fig. 1 B). In the presence of BAPTA, $\tau_{\text {fast }}$ was slowed to $2.1 \mathrm{~s}$ and reduced in amplitude $(56 \%)$. At an interpulse interval of $2 \mathrm{~s}$, the PPR was significantly reduced relative to control conditions $(0.43 \pm 0.06 ; n=7 ; \mathrm{P}=0.006)$. In the second approach, we bath-applied a low concentration of the L-type $\mathrm{Ca}^{2+}$ channel antagonist nifedipine $(3 \mu \mathrm{M}$; Fig. $1 \mathrm{C})$. In separate experiments, this reduced $I_{\mathrm{Ca}}$ charge density by $\sim 40 \%$, from $150 \pm 10 \mathrm{fC} / \mathrm{pF}(n=18)$ to $91 \pm 10 \mathrm{fC} / \mathrm{pF}$ $(n=7 ; \mathrm{P}=0.0015)$. In the presence of nifedipine, the PPR at a 2-s interval was reduced to $0.40 \pm 0.001(n=5$; $\mathrm{P}=0.0009) . \tau_{\text {fast }}$ was slowed to $1.4 \mathrm{~s}$ and reduced in amplitude to $37 \%$.

$\mathrm{CaM}$ is responsible for mediating the $\mathrm{Ca}^{2+}$-dependent acceleration of replenishment at the calyx of Held (Sakaba and Neher, 2001). We performed several experiments to test whether CaM might also accelerate replenishment in cones (Fig. 2). Bath application of a membrane-permeant inhibitor of $\mathrm{CaM}, 20 \mu \mathrm{M}$ calmidazolium (Fig. 2 A), had similar effects to BAPTA or nifedipine, slowing the recovery from depression by both slowing the fast time constant $\left(\tau_{\text {fast }}=2.0 \mathrm{~s}\right)$ and reducing its amplitude to $33 \%$ (Table 1). At an interval of $2 \mathrm{~s}$, the PPR was $0.32 \pm 0.03(n=4)$, significantly smaller than in control conditions $(\mathrm{P}=0.000074)$.

We also disrupted CaM by introducing a peptide derived from the CaM-binding domain of MLCK through the patch pipette (Fig. 2, B and C). With a control version of this peptide (MLCK-control), the time course of recovery could be fit with two exponential functions with $\tau_{\text {fast }}=951 \mathrm{~ms}(68 \%)$ and $\tau_{\text {slow }}=17.6 \mathrm{~s}(n=5)$. When the cone was dialyzed with the active MLCK peptide, the proportion of recovery mediated by the fast component was reduced to $24 \%$, yet the time constant was very similar to MLCK-control $\left(\tau_{\text {fast }}=916 \mathrm{~ms}\right)$. At an interstimulus interval of $2 \mathrm{~s}$, the PPR in the presence of the MLCK peptide was significantly reduced relative to MLCK-control (MLCK-control: $0.66 \pm 0.07, n=5$; MLCK: $0.35 \pm$ $0.05, n=17 ; \mathrm{P}=0.002)$.

After exocytosis, membrane is retrieved by a process of compensatory endocytosis that plays an important role in maintaining a supply of vesicles at the synapse (Wu et al., 2007) and clearing debris from vesicle release sites to allow for subsequent exocytosis (Neher, 2010). At the calyx of Held, all forms of endocytosis depend on $\mathrm{Ca}^{2+}$ and $\mathrm{CaM}$, and inhibition of CaM slows the rate of replenishment (Wu et al., 2009; Sun et al., 2010; Yao and Sakaba, 2012). However, using capacitance recording techniques to monitor vesicle fusion and membrane retrieval (Fig. 3, A and B), we found that endocytosis in cones was unaffected when cones were dialyzed with the MLCK peptide. With the MLCK-control peptide, the time course of endocytosis, measured as the time from the end of the depolarizing step to $50 \%$ recovery $\left(t_{50}\right)$, was $310 \pm 27 \mathrm{~ms}(n=4)$. With the active MLCK peptide, the $t_{50}$ was $301 \pm 53 \mathrm{~ms}(n=7$; $\mathrm{P}=0.89$ ). Endocytosis in cones does not require dynamin and is much faster than in other cells where endocytosis is regulated by CaM (Wu et al., 2009; Sun et al., 2010; Van Hook and Thoreson, 2012). The finding that CaM did not affect cone endocytosis suggests that the slowed recovery from depression is unlikely to be the result of either reduced supply of vesicles in the cone terminal or inhibited release site clearance.

TABLE 1

Fit parameters for paired pulse experiments

\begin{tabular}{|c|c|c|c|c|c|c|}
\hline Parameter & 5 mM EGTA (control) & 1 mM BAPTA & $3 \mu \mathrm{M}$ nifedipine & $20 \mu \mathrm{M}$ Calm. & $20 \mu \mathrm{M}$ MLCK-control & $20 \mu \mathrm{M}$ MLCK \\
\hline \multicolumn{7}{|c|}{ Unconstrained } \\
\hline$\tau_{\text {fast }}(\mathrm{s})$ & 0.816 & 2.1 & 1.39 & 1.98 & 0.951 & 0.917 \\
\hline$\%$ fast & 75.7 & 56.2 & 37.1 & 33.1 & 68.1 & 23.9 \\
\hline$\tau_{\text {slow }}(\mathrm{s})$ & 12.9 & 28.8 & 17.6 & 25.9 & 17.6 & 13.8 \\
\hline $\mathrm{R}^{2}$ & 0.97 & 0.99 & 0.99 & 0.99 & 0.98 & 1.0 \\
\hline \multicolumn{7}{|c|}{ Constrained } \\
\hline$\tau_{\text {fast }}(\mathrm{s})$ & & $0.816^{\mathrm{a}}$ & $0.816^{\mathrm{a}}$ & $0.816^{\mathrm{a}}$ & & $0.951^{\mathrm{b}}$ \\
\hline$\%$ fast & & 22.1 & 26.9 & 17.5 & & 25.3 \\
\hline$\tau_{\text {slow }}(\mathrm{s})$ & & 9.56 & 12.2 & 17.4 & & 14.1 \\
\hline $\mathrm{R}^{2}$ & & 0.97 & 0.99 & 0.99 & & 1.0 \\
\hline$n$ & 10 & 7 & 5 & 4 & 6 & 17 \\
\hline
\end{tabular}

The time course of recovery from synaptic depression was fit with two exponential functions. When fits were constrained to the fast time constant $\left(\tau_{\text {fast }}\right)$ from control conditions, the quality of the fit $\left(\mathrm{R}^{2}\right)$ was comparable with that when the fits were unconstrained. Calm., calmidazolium.

${ }^{a}$ Fits constrained to $\tau_{\text {fast }}$ for $5 \mathrm{mM}$ EGTA control condition $(0.816 \mathrm{~s})$.

${ }^{\mathrm{b}} \mathrm{Fit}$ constrained to $\tau_{\text {fast }}$ MLCK-control condition (0.951 s). 
Because the $\mathrm{Ca}^{2+} / \mathrm{CaM}$-dependent protein kinase CaMKII can increase single-channel conductance (Derkach et al., 1999) and regulate the membrane localization
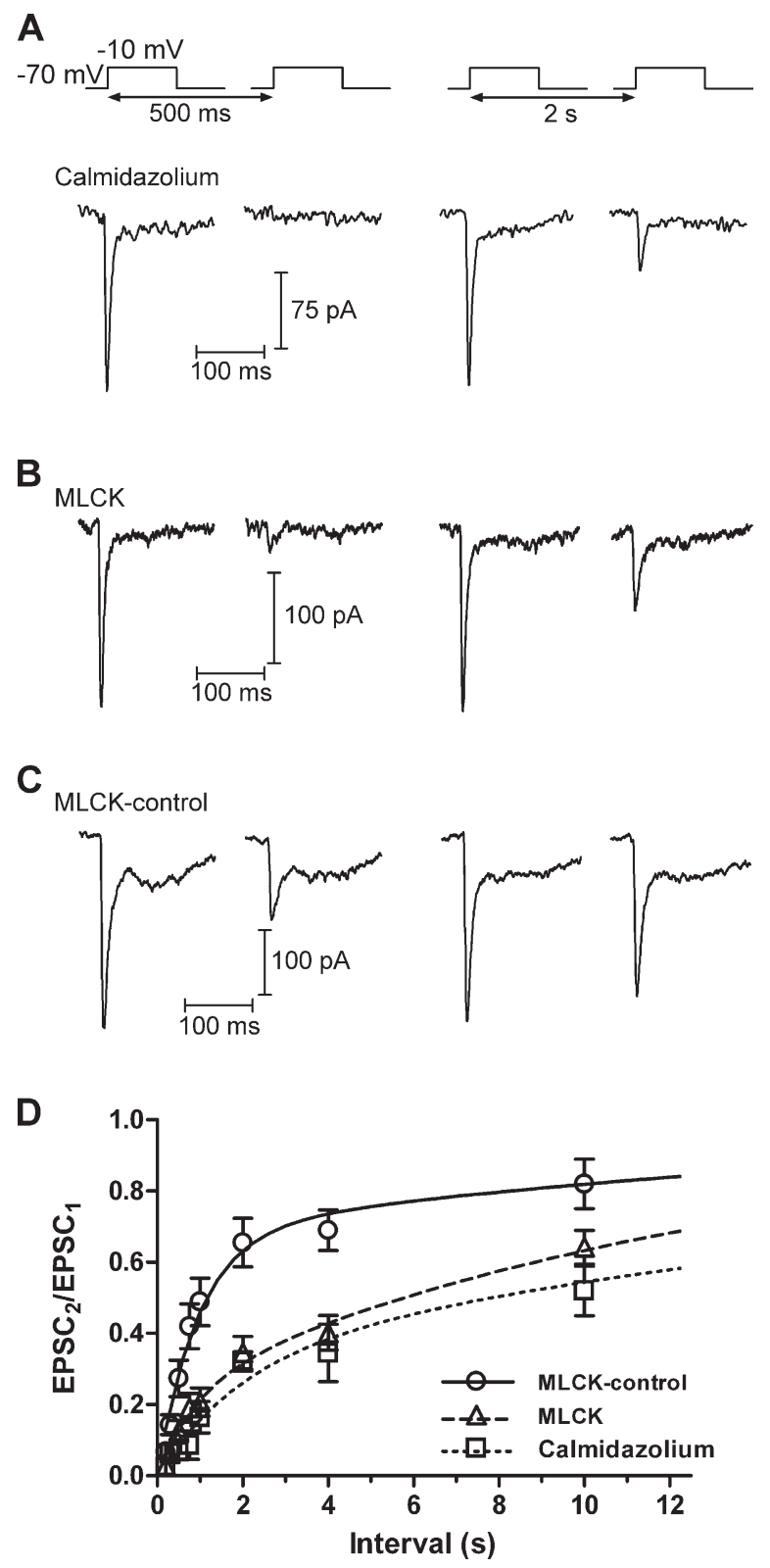

Figure 2. Recovery from synaptic depression depends on CaM. (A) In a paired recording of a cone and an HC, there was minimal recovery from synaptic depression after an interstimulus interval of $500 \mathrm{~ms}$ when the retinal slices were treated with the membranepermeant CaM inhibitor calmidazolium $(20 \mu \mathrm{M})$. The EPSC recovered only partially after an interval of $2 \mathrm{~s}$. (B) Likewise, when cones were dialyzed with a CaM-inhibiting MLCK $(20 \mu \mathrm{M})$, recovery from synaptic depression was inhibited. (C) Recovery from synaptic depression resembled controls (Fig. 1) when the cone was dialyzed with a control version of the MLCK peptide (MLCKcontrol; $20 \mu \mathrm{M}$ ). (D) Group data. Recovery from synaptic depression was slowed when CaM was inhibited. In the presence of calmidazolium, $\tau_{\text {fast }}=1.98 \mathrm{~s}(33 \%)$ and $\tau_{\text {slow }}=25.9 \mathrm{~s}$. With MLCK, $\tau_{\text {fast }}=917 \mathrm{~ms}(23 \%)$ and $\tau_{\text {slow }}=13.8 \mathrm{~s}$. With MLCK-control, $\tau_{\text {fast }}=$ $951 \mathrm{~ms}(68.1 \%)$ and $\tau_{\text {slow }}=17.6 \mathrm{~s}$. Mean \pm SEM is shown.
(Hayashi et al., 2000) of AMPA receptors, we also tested whether the bath-applied CaM inhibitor calmidazolium affects glutamate receptor currents in HCs (Fig. $3 \mathrm{~B}$ ), which are carried principally by AMPA receptors (Cadetti et al., 2005). To do this, we recorded HC currents triggered by photolytic uncaging of MNI-glutamate $(1 \mathrm{mM})$ with a pair of strong UV flashes (1-ms duration, 500-ms interval). In these experiments, neither the amplitude nor the PPR of the AMPA currents were affected by calmidazolium. In control conditions, AMPA receptor currents evoked by the first flash had a mean amplitude of $262 \pm 43 \mathrm{pA}$ and a PPR of $0.95 \pm 0.02$ $(n=4)$. In the presence of $20 \mu \mathrm{M}$ calmidazolium, the responses were not significantly different, with a mean amplitude of $213 \pm 51 \mathrm{pA}(\mathrm{P}=0.49)$ and a PPR of $0.96 \pm$ $0.02(\mathrm{P}=0.71 ; n=5)$. Combined with our finding that CaM inhibitors introduced into individual presynaptic cones through patch pipettes have similar effects to bath-applied calmidazolium, this indicates that effects of calmidazolium are presynaptic.

Because CaM can regulate L-type $I_{\mathrm{Ca}}$ and changes in $\mathrm{Ca}^{2+}$ influx can contribute to synaptic depression (Forsythe et al., 1998; Griessmeier et al., 2009), we tested whether CaM inhibition affected cone $I_{\mathrm{Ca}}$ (Fig. 3, $\mathrm{C}$ and $\mathrm{D})$. However, inhibition of CaM with either the MLCK peptide or calmidazolium had no effect on either the voltage dependence or charge of cone $I_{\mathrm{Ca}}$ $\left(Q_{\mathrm{Ca}}\right)$. The voltage of half-maximal activation $\left(V_{50}\right)$ of cone $I_{\mathrm{Ca}}$ was $-26 \pm 1 \mathrm{mV}(n=18)$ in control conditions and $-25 \pm 2 \mathrm{mV}$ in the presence of calmidazolium $(n=8$; $\mathrm{P}=0.48) . V_{50}$ was $-29 \pm 1 \mathrm{mV}(n=6)$ when cones were dialyzed with the MLCK-control peptide and $-31 \pm$ $1 \mathrm{mV}(n=11 ; \mathrm{P}=0.16)$ when cones were dialyzed with MLCK. At the peak $(-10 \mathrm{mV})$, the $\mathrm{Ca}^{2+}$ charge density was $0.15 \pm 0.01 \mathrm{pC} / \mathrm{pF}(n=18)$ in control conditions. In the presence of calmidazolium, it was not significantly different $(0.17 \pm 0.02 \mathrm{pC} / \mathrm{pF} ; n=9 ; \mathrm{P}=0.17)$. In paired pulse experiments (Fig. $3 \mathrm{D}$ ), $Q_{\mathrm{Ca}}$ facilitated at relatively short interpulse intervals, similar to a previous study (Kourennyi and Barnes, 2000). However, the PPR of $Q_{\mathrm{Ca}}\left(Q_{\mathrm{Ca} 2} / Q_{\mathrm{Ca} 1}\right)$ was not affected by the CaM inhibitor ( $\mathrm{P}>0.05$ for all data points).

The quantal parameters, quantal amplitude $(Q)$, size of the available vesicle pool $(\mathrm{N})$, and release probability $\left(\mathrm{P}_{\mathrm{r}}\right)$, appeared to be unaffected by CaM inhibitors. Quantal amplitude of mEPSCs (Fig. S1) was not significantly altered by calmidazolium (control $=8.8 \pm 4.4 \mathrm{pA}$, $n=1,107$ events from $10 \mathrm{HCs}$; calmidazolium $=8.9 \pm$ $4.4 \mathrm{pA}, n=605$ events from $6 \mathrm{HCs} ;$ mean $\pm \mathrm{SD} ; \mathrm{P}=0.17$, Kolmogorov-Smirnov test). 25-ms steps to $-10 \mathrm{mV}$ stimulate large EPSCs, reflecting release of the entire IRP with release probability of 1 (Bartoletti et al., 2010). EPSC amplitude was not changed by CaM inhibitors, indicating that pool size was unchanged (control $=133$ $\pm 20 \mathrm{pA}, n=17$; calmidazolium $=141 \pm 3 \mathrm{pA}, n=6, \mathrm{P}=$ $0.79 ;$ MLCK-control $=142 \pm 22, n=14 ;$ MLCK $=143 \pm 14$, 
$n=16 ; \mathrm{P}=0.94)$, and trains of pulses (25-ms pulses, $13.3 \mathrm{~Hz}$; Fig. 4) showed that the entire pool continued to be released by the first pulse after inhibiting $\mathrm{CaM}$, indicating that release probability remained near 1 (Bartoletti et al., 2010).

In addition to using paired pulse protocols to assess replenishment, we stimulated cones with trains of depolarizing pulses $(25-\mathrm{ms}$ pulses, $13.3 \mathrm{~Hz}, 4 \mathrm{~s})$ while recording the postsynaptic currents in HCs (Fig. 4). The initial test pulse in the train empties the IRP and the maintained train of pulses empties the remainder of the releasable pool of vesicles (Babai et al., 2010; Bartoletti et al., 2010). Release soon reaches a steady-state where it is limited by the rate of replenishment (Sakaba et al., 2002; Schneggenburger et al., 2002; Babai et al., 2010). The rate of replenishment can therefore be measured from a linear fit to the cumulative increase in the charge transfer of postsynaptic currents. Previous work showed that replenishment measured in this way in cones is accelerated when the intraterminal $\left[\mathrm{Ca}^{2+}\right]$ is increased

\section{A Endocytosis}
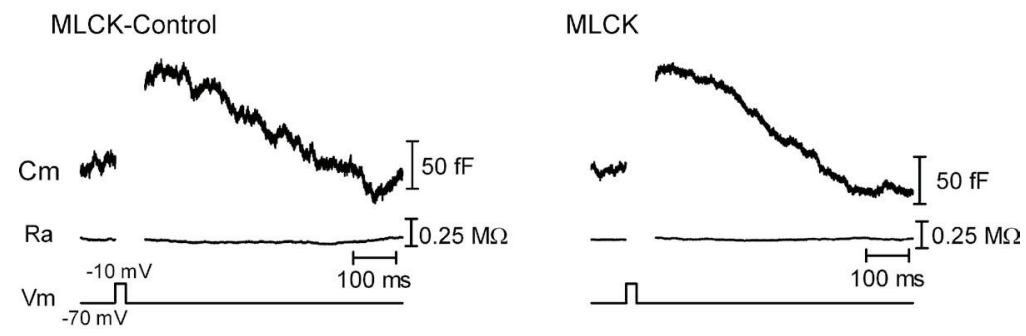

B

Horizontal cell AMPA receptors

Control

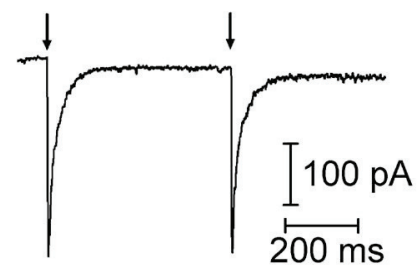

C

Cone calcium currents

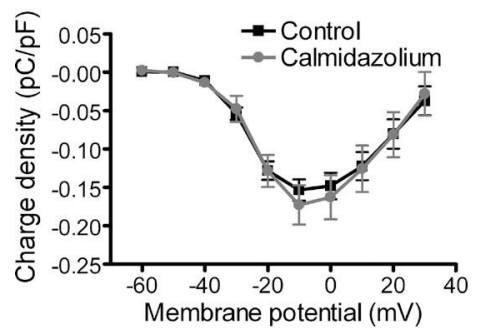

D

\section{Calcium current facilitation}

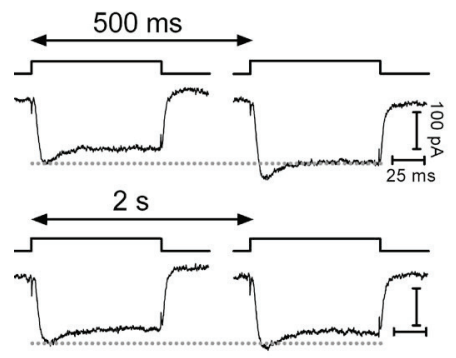

Calmidazolium
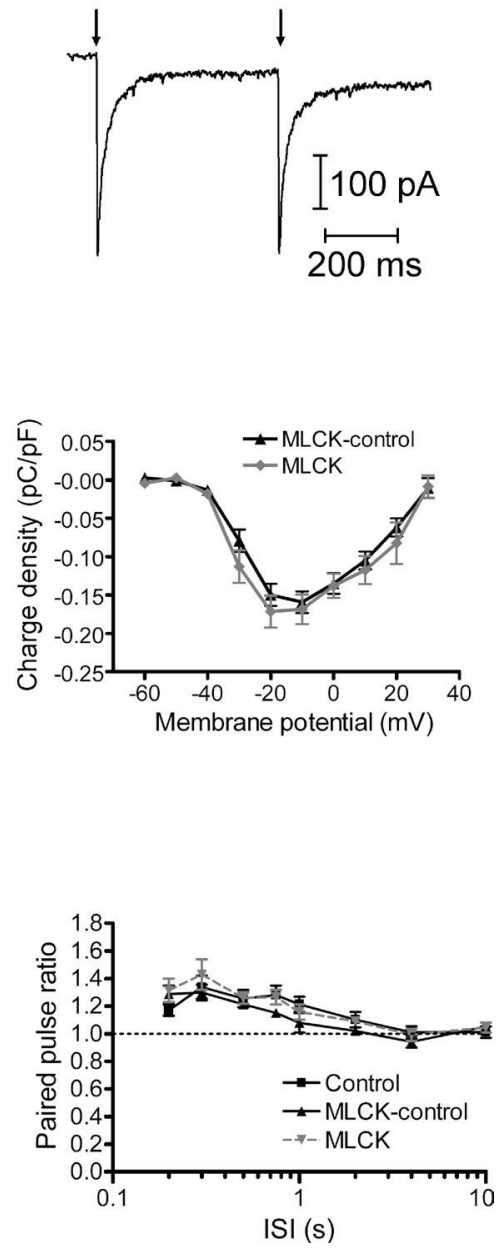

Figure 3. CaM inhibitors do not affect rapid endocytosis, HC glutamate receptors, or cone $\mathrm{Ca}^{2+}$ currents $\left(I_{\mathrm{Ca}}\right)$. (A) Whole-cell capacitance recordings from cones that were dialyzed with either the MLCKcontrol (left) or MLCK (right) peptides $(20 \mu \mathrm{M})$. There was a brief increase in whole-cell capacitance in response to a $25-\mathrm{ms}$ depolarizing step to $-10 \mathrm{mV}$ from a holding potential of $-70 \mathrm{mV}$, resulting from fusion of synaptic vesicles. The capacitance then decayed back toward baseline as vesicle membrane was retrieved via endocytosis. There was no change in access resistance $(\mathrm{Ra})$. (B) Pairs of HC AMPA receptor currents were evoked by uncaging of MNI-glutamate $(1 \mathrm{mM})$ with short (1 ms) UV flashes (500-ms interval) in control conditions (left) and, in a second $\mathrm{HC}$, in the presence of $20 \mu \mathrm{M}$ calmidazolium (right). Neither the amplitude nor the PPR was altered by calmidazolium. (C) Charge-voltage plots of leaksubtracted cone $I_{\mathrm{Ca}}$ recorded in response to $100-\mathrm{ms}$ steps from -60 to $30 \mathrm{mV}$ from a holding potential of $-70 \mathrm{mV}$. The charge was normalized to whole-cell capacitance. Neither the amplitude nor the voltage dependence of $I_{\mathrm{Ca}}$ was affected by calmidazolium (20 $\mu \mathrm{M}$, left) or the MLCK peptide $(20 \mu \mathrm{M}$, right $)$. (D) The PPR of $\mathrm{Ca}^{2+}$ charge $\left(Q_{\mathrm{Ca} 2} / Q_{\mathrm{Ca} a}\right)$ facilitated in response to pairs of depolarizing pulses (steps to $-10 \mathrm{mV}$ from $-70 \mathrm{mV}, 100$-ms duration with intervals of $200 \mathrm{~ms}$ to $10 \mathrm{~s}$ ). This facilitation was unaffected when cones were dialyzed with the MLCK or MLCK-control peptides. Mean \pm SEM is shown. 
either by further depolarization during the trains (from pulses of -30 to $-10 \mathrm{mV}$ ) or by lengthening the test pulse duration (from 25 to $50 \mathrm{~ms}$ at $-10 \mathrm{mV}$; Babai et al., 2010). To test whether these $\mathrm{Ca}^{2+}$-dependent effects are mediated by CaM, we performed these experiments when cones were dialyzed with either the MLCK-control or MLCK peptides $(20 \mu \mathrm{M})$.

When cones were dialyzed with MLCK-control, the slope of the cumulative charge transfer increased by a factor of $2.4 \pm 0.3(n=12)$ when the pulse potential was changed from -30 to $-10 \mathrm{mV}$ to enhance $\mathrm{Ca}^{2+}$ entry (Fig. $4 \mathrm{~A}$ ). When we converted the slope of the cumulative charge transfer to a vesicle release rate (16 fC/vesicle) and scaled it to the amplitude of the postsynaptic current (47 pA/ribbon; Cadetti et al., 2008; Bartoletti et al., 2010, 2011), this corresponded to a change of sustained release rate from $151 \pm 24$ vesicles $(\mathrm{v}) / \mathrm{s} /$ ribbon at $-30 \mathrm{mV}$ to $334 \pm 55 \mathrm{v} / \mathrm{s} /$ ribbon at $-10 \mathrm{mV}(n=16)$. When $\mathrm{Ca}^{2+}$ entry was instead enhanced by lengthening the pulse from 25 to $50 \mathrm{~ms}$, the slope increased by a factor of $1.7 \pm 0.2(n=8$; Fig. 4 C), corresponding to a change from $202 \pm 50$ to $299 \pm 55 \mathrm{v} / \mathrm{s} /$ ribbon. In the presence of the active MLCK peptide, increasing $\left[\mathrm{Ca}^{2+}\right]$ had a smaller effect on the slope of the cumulative charge transfer; switching from a pulse potential of -30 to $-10 \mathrm{mV}$ increased the slope only by a factor of $1.4 \pm 0.09(n=25 ; \mathrm{P}=0.02$; Fig. 4 B), a change from $131 \pm 16$ to $174 \pm 21 \mathrm{v} / \mathrm{s} /$ ribbon, and lengthening the pulse increased the slope only by a factor of $1.1 \pm 0.08(n=19 ; \mathrm{P}=0.02$; Fig. $4 \mathrm{D})$, which represented a change from $100 \pm 14$ to $105 \pm 19$ $\mathrm{v} / \mathrm{s} /$ ribbon. Together, these results indicate that the previously reported $\mathrm{Ca}^{2+}$-mediated acceleration of replenishment at the cone synapse (Babai et al., 2010) is the result of an enhancement of vesicle resupply by $\mathrm{Ca}^{2+} / \mathrm{CaM}$.

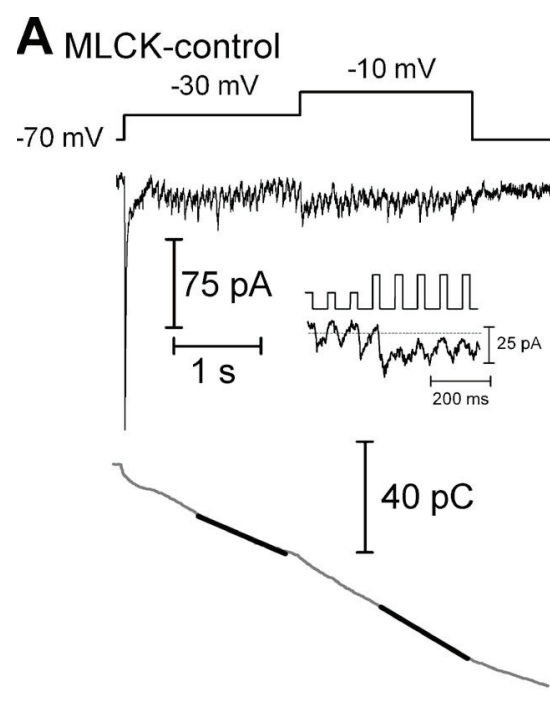

C

MLCK-control

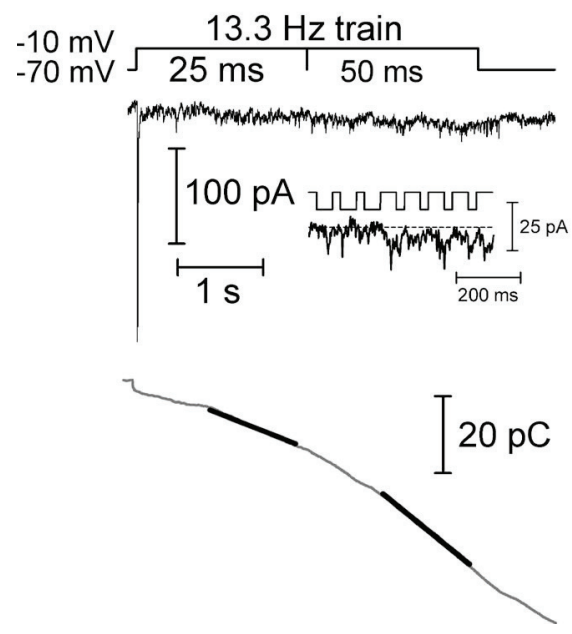

B MLCK
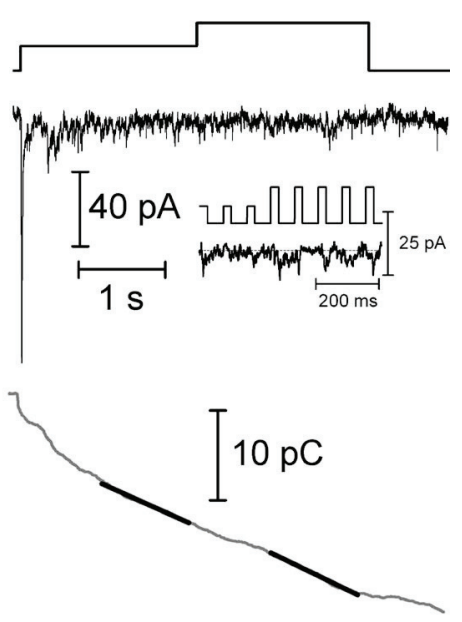

D MLCK

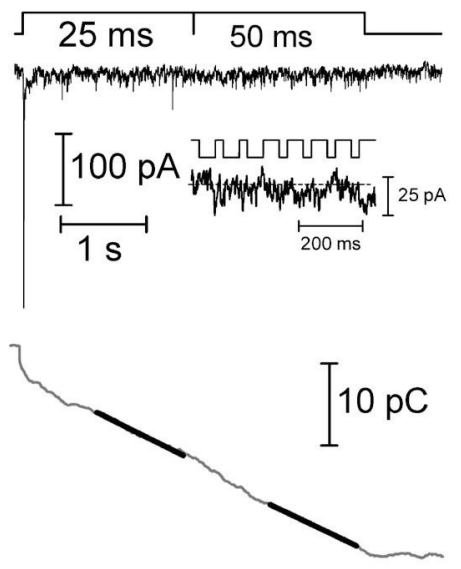

Figure 4. $\mathrm{Ca}^{2+}$-dependent acceleration of replenishment measured using trains of depolarizing pulses. (A) In a paired recording of a cone and $\mathrm{HC}$ in which the cone was dialyzed with the MLCK-control peptide $(20 \mu \mathrm{M})$, the cone was stimulated with a train of depolarizing pulses to $-30 \mathrm{mV}$ (25-ms duration, $13.3 \mathrm{~Hz}$ ), evoking an EPSC in the HC (top). After $2 \mathrm{~s}$, the step amplitude was increased to $-10 \mathrm{mV}$ to fully activate the $\mathrm{Ca}^{2+}$ current, accelerating replenishment. The inset shows the EPSC at the transition from steps to $-30 \mathrm{mV}$ to steps to $-10 \mathrm{mV}$. The trace at the bottom shows the cumulative charge transfer obtained by integrating the EPSC waveform. The slope of a line (black line) fit to the final $1 \mathrm{~s}$ of the cumulative charge transfer of the EPSC in each experimental condition provides a measure of the rate of replenishment. (B) In a similar experiment, the cone was dialyzed with the MLCK peptide $(20 \mu \mathrm{M})$. This inhibited the $\mathrm{Ca}^{2+}$-dependent acceleration of replenishment when the step amplitude was increased. (C) In a cone-HC paired recording in which the cone was dialyzed with the MLCK-control peptide, replenishment was accelerated when the depolarizing step $(-70$ to $-10 \mathrm{mV})$ was lengthened from 25 to $50 \mathrm{~ms}$. (D) This acceleration was inhibited when a cone was instead dialyzed with the MLCK peptide. 
Sites of $\mathrm{Ca}^{2+} / \mathrm{CaM}$ effects on replenishment

At goldfish $\mathrm{BC}$ synaptic ribbons, $\mathrm{Ca}^{2+}$ regulates transfer of vesicles at two points, from a cytoplasmic pool into a ribbon-associated reserve pool and from the ribbon reserve pool to a readily releasable pool at the base of the ribbon (Gomis et al., 1999). At cone synapses, the second, slower kinetic component of release is thought to represent the transition of a ribbon-associated reserve pool of vesicles to release sites at the ribbon base (Bartoletti et al., 2010). If this transition is the point of CaM regulation of replenishment in cones, inhibition of CaM should slow the second component of cone exocytosis. To test this, we fit the cumulative charge transfer of EPSCs recorded in HCs in response to a 100-ms depolarization of a presynaptic cone with two exponentials (Fig. 5). The second kinetic component $\left(\tau_{\text {slow }}\right)$ had a time constant of $172 \pm 14 \mathrm{~ms}(n=7)$ in control conditions and $165 \pm 32 \mathrm{~ms}(n=4 ; \mathrm{P}=0.85)$ in the presence of $20 \mu \mathrm{M}$ calmidazolium. Similarly, $\tau_{\text {slow }}$ was $175 \pm 49 \mathrm{~ms}$ $(n=5)$ when cones were dialyzed with $20 \mu \mathrm{M}$ MLCKcontrol peptide and $195 \pm 21 \mathrm{~ms}(n=13 ; \mathrm{P}=0.71)$ when cones were dialyzed with $20 \mu \mathrm{M}$ MLCK peptide. The kinetics and amplitude of the initial fast release component were also unaffected by inhibition of CaM. In control conditions, $\tau_{\text {fast }}=6.1 \pm 0.4 \mathrm{~ms}, 21 \pm 2 \%(n=7)$. In the presence of calmidazolium, $\tau_{\text {fast }}$ was $5.9 \pm 0.3 \mathrm{~ms}$ $(\mathrm{P}=0.73), 21 \pm 6 \%(n=4 ; \mathrm{P}=0.97)$. With the MLCKcontrol peptide, $\tau_{\text {fast }}$ was $7.6 \pm 0.7 \mathrm{~ms}, 25 \pm 5 \%(n=5)$. With the MLCK peptide, $\tau_{\text {fast }}$ was $6.9 \pm 0.4 \mathrm{~ms}(n=13$; $\mathrm{P}=0.41), 24 \pm 3 \%(\mathrm{P}=0.71)$. Together, these data suggest that $\mathrm{Ca}^{2+}$ and $\mathrm{CaM}$ do not act to quicken movement of vesicles from the ribbon-associated reserve pool to release sites at the ribbon base nor do they speed the fusion of vesicles in the IRP. Additionally, using TIRFM imaging of single vesicle fusion events, we found that individual vesicles dwell at the membrane for only $\sim 47$ ms before fusing, a latency which is too short to be rate limiting in the replenishment process (Fig. S2).

\section{Analytical model of vesicle resupply}

To test whether resupply of vesicles to the ribbon might be the rate-limiting step in replenishment, we developed a three-dimensional random walk model of vesicle diffusion (Fig. 6). We modeled vesicle diffusion in the synapse as spherical vesicles undergoing random walks in a three-dimensional rectangular lattice of spacing $\delta$. After each time step, $\Delta t$, each vesicle moves to an adjacent lattice site. The (macroscopic) diffusion coefficient, $D=\delta^{2} /(2 \Delta t)$, relates $\delta$ and $\Delta t$ in the (microscopic) random walk model, so these quantities cannot be chosen independently (Berg, 1983). We assumed each lattice site can be occupied by at most one vesicle and that the occupation probabilities for distinct lattice sites are independent; these assumptions can only be satisfied by choosing $\delta$ equal to the vesicle diameter.

When a vesicle collides with a given lattice site on the ribbon (i.e., a tethering site), the probability of successful attachment is given by $s p$, where $p$ denotes the probability of the ribbon site becoming occupied in a given time step, and $s$ denotes the attachment probability, that is, the probability that a vesicle colliding with the ribbon will actually "stick" rather than drift away at a future time step. We assumed vesicles of density $\rho$ are distributed randomly and uniformly within the synaptic
A
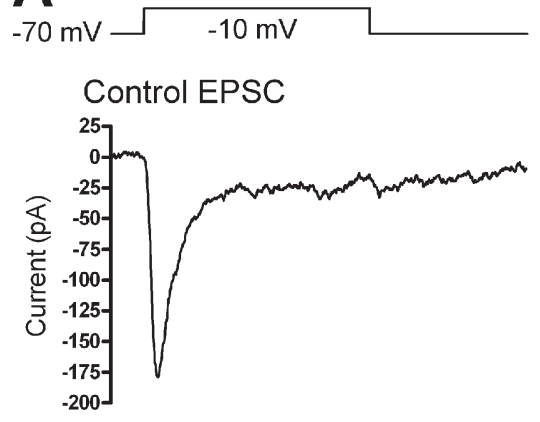

\section{B}

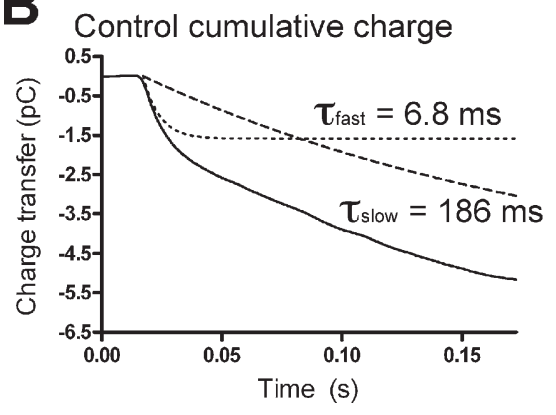

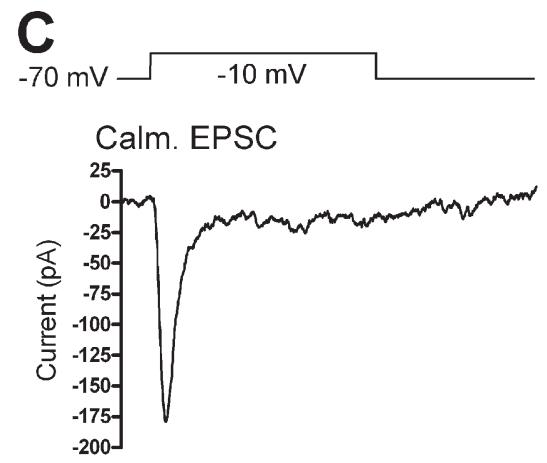

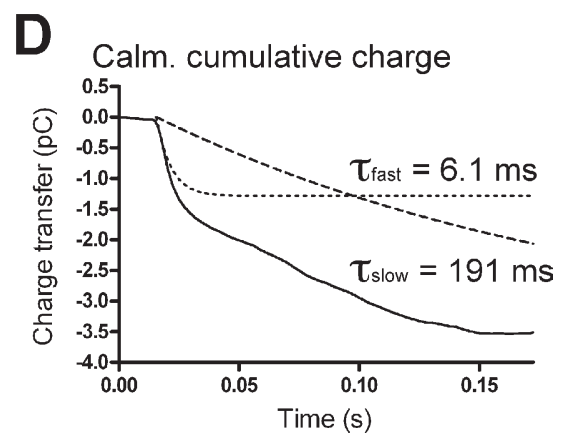

Figure 5. Cone release kinetics. (A) EPSC recorded under control conditions in an HC in response to a $100-\mathrm{ms}$ depolarization of a presynaptic cone. (B) The cumulative charge transfer of the EPSC was fit with two exponential functions, with $\tau_{\text {fast }}=6.8 \mathrm{~ms}$ and $\tau_{\text {slow }}=$ $186 \mathrm{~ms}$. (C and D) Recording from another cone-HC pair in the presence of calmidazolium (Calm.; $20 \mu \mathrm{M}$ ). Similar to the control recording, the cumulative charge transfer (D) was fit with two exponential functions with $\tau_{\text {fast }}=6.1 \mathrm{~ms}$ and $\tau_{\text {slow }}=191 \mathrm{~ms}$. 
terminal, so that the probability of a lattice site becoming occupied is independent from one time step to the next and equal to the vesicle density per lattice site, $\rho \delta^{3}$. Because ribbon sites can only be accessed from one side, we have

$$
p=\frac{1}{2} \rho \delta^{3} .
$$

The probability of having to wait at least $t$ seconds before a vesicle successfully attaches to a given site is given by $P(t)=$ $(1-s p)^{t / \Delta t}$, with $t / \Delta t$ the total number of time steps that
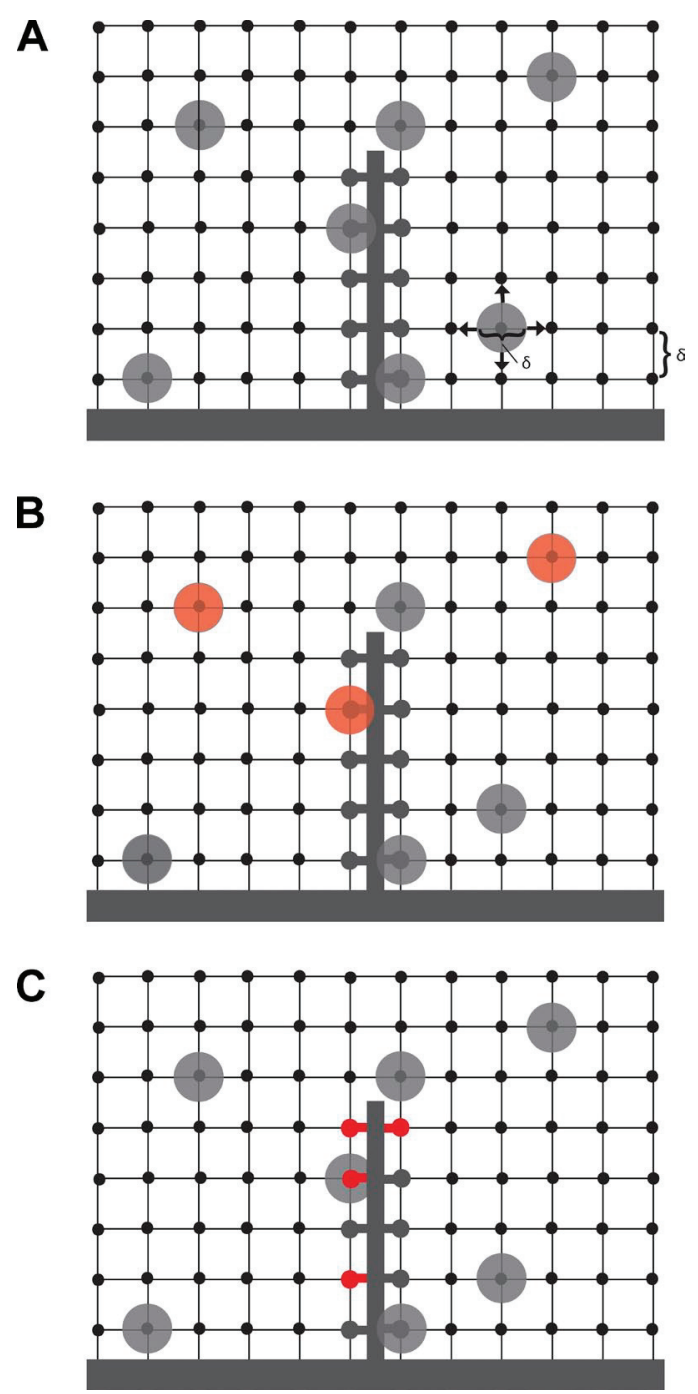

Figure 6. Model of ribbon replenishment. (A) The terminal was modeled as a three-dimensional rectangular lattice of vesicle sites separated by $\delta$, the diameter of a single vesicle $(\delta=45 \mathrm{~nm})$. This space was populated with vesicles at a density of $\rho=2234 \mathrm{v} / \mu \mathrm{m}^{3}$ that move through the terminal with a diffusion coefficient $D=$ $0.11 \mathrm{\mu m}^{2} / \mathrm{s}$. The terminal also contains a synaptic ribbon, which has 110 vesicle attachment sites. (B and C) Two simple variations of the model in which CaM acts to alter the vesicle attachment probability by acting on either vesicles themselves $(B$, red) or vesicle attachment sites on the ribbon $(\mathrm{C}$, red). have elapsed in $t$ seconds. Assuming all sites are empty at $t=0$, the expected number of vesicle attachment sites that are filled at time $t$ is given by $a(t)=n(1-P(t))$, where $n$ is the maximum number of vesicles that can occupy the ribbon. Taking $\ln P(t)$, using the approximation $\ln (1+x) \approx x$ for small $x$, and substituting

$$
\Delta t=\frac{\delta^{2}}{2 D}
$$

and

$$
p=\frac{1}{2} \rho \delta^{3}
$$

we find that $P(t) \approx e^{-t / \tau_{a}}$ and $a(t)=n\left(1-e^{-t / \tau_{a}}\right)$, where

$$
\tau_{a}=\frac{1}{D \rho \delta s}
$$

is a fundamental time constant governing the rate of vesicle resupply. Although we derived this model to describe behavior at ribbon synapses, it is important to note that because it makes minimal assumptions about the geometry of the synapse, it should also hold true for vesicle resupply of other synapses, provided the vesicles exhibit random motion.

Because it models the time constant underlying the replenishment process, the formula for $\tau_{a}$ does not depend on ribbon size. However, $a(t)$, the expected number of vesicles on the ribbon at time $t$, does rely on ribbon size, as it is proportional to $n$. In particular, the number of vesicles hitting the ribbon per second is given by the hit rate

$$
h(t)=\frac{d a}{d t}=\frac{n}{\tau_{a}} e^{-t / \tau_{a}},
$$

where at $t=0$ we assume the ribbon is empty. At $t=0$ and for $s=1$, we obtain a hit rate of

$$
h(0)=\frac{n}{\tau_{a}}=n D \rho \delta,
$$

which is proportional to ribbon size and in close agreement with the hit rate described for hair cell ribbons by Graydon et al. (2011).

To explore whether the rate of vesicle collisions is itself rate limiting, we first assumed that all ribbon collisions result in successful attachment $(s=1)$, yielding a lower bound on the replenishment time constant, $\tau_{a}$. Using empirically determined values from photoreceptor synapses of $D=0.11 \mu^{2} / \mathrm{s}, \rho=2,210 \mathrm{v} / \mu^{3}$, and $\delta=$ $45 \mathrm{~nm}$ (Rea et al., 2004; Thoreson et al., 2004; Sheng et al., 2007), we obtained $\tau_{a}=91 \mathrm{~ms}$. This is roughly an order of magnitude faster than the experimentally measured value for $\tau_{a}$. Likewise, using $n=110$ (Bartoletti et al., 2010), 
we calculated $h(0)=1,203 \mathrm{v} / \mathrm{s} /$ ribbon. To maintain release during a prolonged depolarization, vesicles must be supplied to a depleted ribbon at least as fast as the rate of release. However, this value of vesicle collisions is severalfold faster than the sustained release rate $(\sim 300 \mathrm{v} / \mathrm{s} /$ ribbon $)$ measured with trains of depolarizing pulses (Fig. 4). Together, these findings indicate that other factors beyond the rate of vesicle collisions with the ribbon, such as an attachment probability, $s<1$, are likely to play a role in slowing down vesicle replenishment.

We next used the model to assess two different mechanisms by which $\mathrm{Ca}^{2+} / \mathrm{CaM}$ might regulate attachment probability, $s$, and thereby regulate vesicle resupply and replenishment. To do so, we derived two simple variations of the model (Fig. 6, B and C).

Model 1: Changes in stickiness (attachment probability) occur on the vesicles. Here we assumed there are two populations of vesicles: those in population A have a higher attachment probability, $s_{\mathrm{A}}$, when they collide with the ribbon, whereas those in population $\mathrm{B}$ have a lower attachment probability, $s_{\mathrm{B}}<s_{\mathrm{A}}$. Because each ribbon site is the same, the probability that vesicle collision results in attachment is simply given by the weighted mean of the individual attachment probabilities, $s=f s_{\mathrm{A}}+$ $(1-f) s_{\mathrm{B}}$, where $f$ is the fraction of vesicles in population A. As before, the expected number of vesicles on the ribbon at time $t$ is

$$
a(t)=n\left(1-e^{-t / \tau_{a}}\right)
$$

where

$$
\tau_{a}=\frac{1}{D \rho \delta s}
$$

and $s$ is now the mean attachment probability computed above. If the effect of $\mathrm{Ca}^{2+} / \mathrm{CaM}$ is to change the fraction $f$ of vesicles in the stickier population, it would manifest itself as a change in the vesicle replenishment timescale, $\tau_{a}$. For example, if inhibition of $\mathrm{Ca}^{2+} / \mathrm{CaM}$ causes a decrease in $f$, then the model predicts a decrease in $s$ and hence an increase in $\tau_{a}$. Note that this model does not predict the existence of a second timescale even though there are two populations of vesicles.

Model 2: Stickiness changes occur on the ribbon. In this variant of the model, we assumed all vesicles are identical, but there are two distinct populations of tethering sites on the ribbon. The ribbon sites in population A have a higher attachment probability $s_{\mathrm{A}}$, whereas the ribbon sites in population $\mathrm{B}$ have a lower attachment probability, with $s_{\mathrm{B}}<s_{\mathrm{A}}$. The numbers $n_{\mathrm{A}}=f n$ and $n_{\mathrm{B}}=(1-f) n$ give the number of sites in each population, where $f$ is the fraction of ribbon sites in population A. Because attachment probabilities are different for $\mathrm{A}$ and $\mathrm{B}$ ribbon sites, we must use different expressions for $P(t): P_{A}(t)=\left(1-s_{\mathrm{A}} p\right)^{t / \Delta t}$ and $P_{\mathrm{B}}(t)=\left(1-s_{\mathrm{B}} p\right)^{t / \Delta t}$ for populations $\mathrm{A}$ and $\mathrm{B}$, respectively. The result is that the expected number of vesicles on the ribbon at time $t$ is given by the sum of two terms:

$$
a(t)=n_{\mathrm{A}}\left(1-e^{-t / \tau_{\mathrm{A}}}\right)+n_{\mathrm{B}}\left(1-e^{-t / \tau_{\mathrm{B}}}\right),
$$

where

$$
\tau_{\mathrm{A}}=\frac{1}{D \rho \delta s_{\mathrm{A}}}
$$

and

$$
\tau_{\mathrm{B}}=\frac{1}{D \rho \delta s_{\mathrm{B}}}
$$

Because $s_{\mathrm{A}}>s_{\mathrm{B}}$, we have $\tau_{\mathrm{A}}<\tau_{\mathrm{B}}$, so the population A timescale is faster. This model has two qualitative differences with model 1: (1) it predicts a second timescale, and (2) the effect of $\mathrm{Ca}^{2+} / \mathrm{CaM}$ modulation is different. Because $\mathrm{Ca}^{2+} / \mathrm{CaM}$ changes the fraction of ribbon sites $f$ that belong to the stickier population, this manifests itself as a change in the amplitudes $n_{\mathrm{A}}$ and $n_{\mathrm{B}}$ for each component of $a(t)$. For example, if inhibition of $\mathrm{Ca}^{2+} /$ CaM leads to a decrease in $f$, the model predicts a decrease in the amplitude of the fast component, $n_{\mathrm{A}}$, and an increase in the amplitude of the slow component, $n_{\mathrm{B}}$. There is no predicted effect on the time constants, in contrast to model 1.

Model 1 predicts that if $\mathrm{Ca}^{2+} / \mathrm{CaM}$ enhances vesicle attachment by acting on vesicles, then $\mathrm{Ca}^{2+} / \mathrm{CaM}$ inhibition should cause an increase in a single replenishment time constant $\tau_{a}$. Model 2 predicts that if $\mathrm{Ca}^{2+} / \mathrm{CaM}$ enhances vesicle attachment by acting on ribbon sites, the kinetics of vesicle resupply will be governed by two distinct time constants, $\tau_{\mathrm{A}}$ (fast) and $\tau_{\mathrm{B}}$ (slow), and inhibition of $\mathrm{Ca}^{2+} / \mathrm{CaM}$ will cause a decrease in the amplitude associated with the fast component, $\tau_{\mathrm{A}}$, but there will be no change in the values of the two time constants. In paired pulse experiments, we consistently saw a substantial reduction in the amplitude of the fast component after inhibiting $\mathrm{Ca}^{2+}$ or CaM. Although we sometimes observed modest changes in the time constants of replenishment with these manipulations, the $\mathrm{R}^{2}$ values for unconstrained fits $(0.97-1.0)$ were very similar to those for fits in which $\tau_{\text {fast }}$ was held equal to control values (0.96-1.0; Table 1). Whether fits were unconstrained or constrained so that $\tau_{\text {fast }}$ was held constant, the amplitude of $\tau_{\text {fast }}$ was reduced by inhibiting $\mathrm{Ca}^{2+}$ or $\mathrm{CaM}$. This suggests that changes in the amplitude of $\tau_{\text {fast }}$ rather than changes in the time constant itself are the dominant effects of inhibiting CaM. This is consistent with predictions of model 2 where $\mathrm{Ca}^{2+} / \mathrm{CaM}$ acts on ribbon sites. Although a mechanism resembling that of model $1\left(\mathrm{Ca}^{2+} / \mathrm{CaM}\right.$ action on vesicles $)$ might also play a 
role, the effects on $\tau_{\text {fast }}$ were not consistent across experimental conditions.

\section{Synaptic filtering by $\mathrm{Ca}^{2+} / \mathrm{CaM}-$ dependent replenishment} The timing of vesicle resupply at the cone synapse influences the strength of the input to off-responding second-order neurons; more vesicles are made available for release by the maintained hyperpolarization of cones during a long flash than by a short flash (Jackman et al.,
2009). This implies that the synapse acts as a low-pass filter for negative contrast, signaling light-to-dark transitions more strongly after longer light flashes than after shorter flashes. $\mathrm{A} \mathrm{Ca}^{2+} / \mathrm{CaM}$-dependent fast phase of replenishment might therefore be an important contributor to the cones' ability to transmit responses to time-varying stimuli. The following experiments address this possibility.

In the first of these experiments (Fig. 7, A and B), we recorded intraretinal ERG d-wave responses after flashes
A

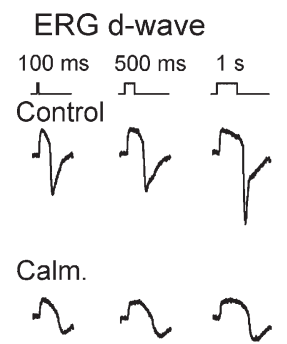

C

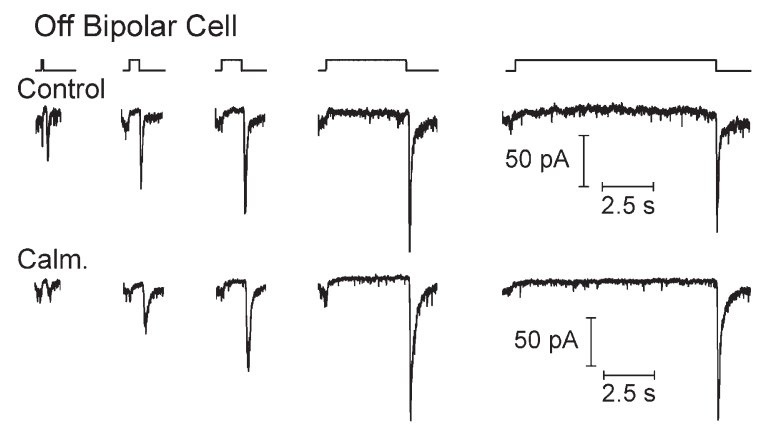

E

Horizontal Cell

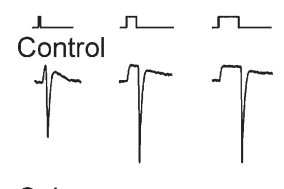

Calm. $r$ r

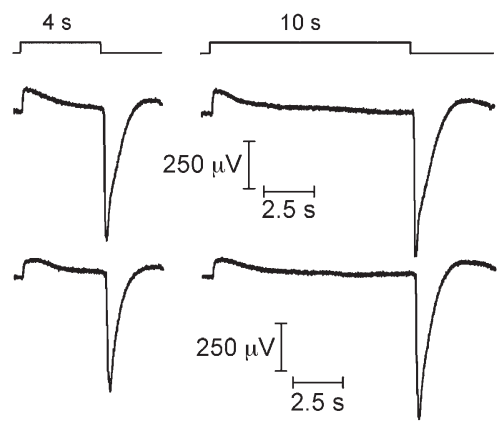

B

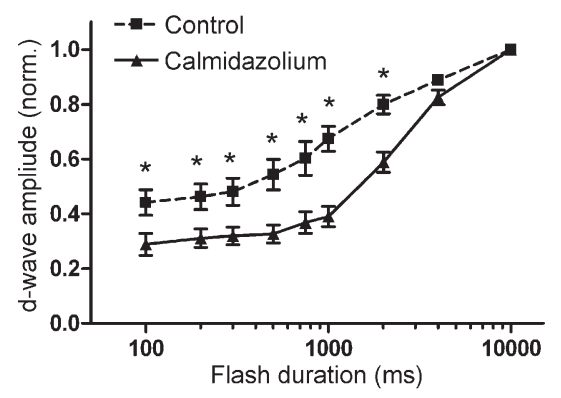

D

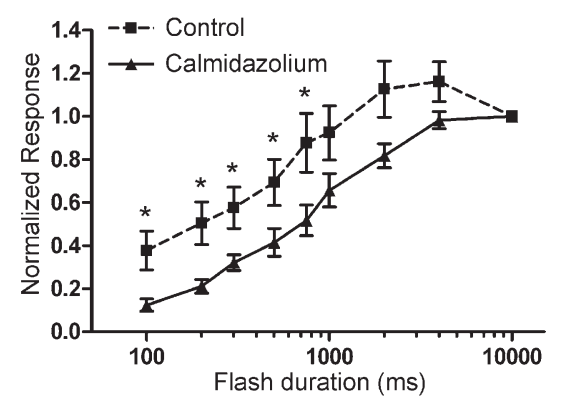

$\mathbf{F}$

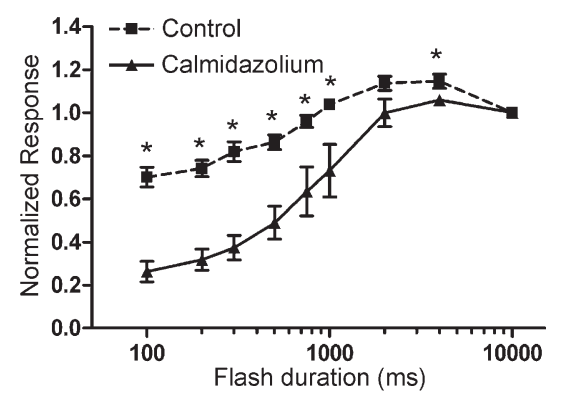

Figure 7. CaM-dependent vesicle replenishment enhances responses at light offset. (A) Intraretinal ERG recordings were made in a superfused eyecup preparation in the presence of $10 \mu \mathrm{M} \mathrm{L-AP4}$ to isolate the d-wave, which is the negative-going peak occurring at light offset in these intraretinal ERG recordings. (top) The amplitude of the d-wave increased with increasing flash duration. (bottom) When the eyecup was bathed with $20 \mu \mathrm{M}$ calmidazolium (Calm.), the d-wave amplitude was reduced after short flashes. (B) Group data showing the reduction in d-wave amplitude when the eyecup was treated with calmidazolium. (C) A similar effect was seen in whole-cell recordings from Off BCs in a retinal slice. (top) The amplitude of a fast inward current at light offset increased with increasing flash duration. (bottom) When the retinal slices were bathed with $20 \mu \mathrm{M}$ calmidazolium, the response was reduced after shorter-duration flashes. (D) Group data of the normalized charge of the response at light offset (integrated over $500 \mathrm{~ms}$ after the end of the flash), showing that the off response in Off BCs was reduced in the presence of calmidazolium. (E and F) Similar flash-duration experiments conducted with whole-cell recordings of HCs. Mean \pm SEM is shown. *, $\mathrm{P}<0.05$. 
of varying duration in a superfused eyecup preparation. The ERG d-wave is a population response originating largely from Off $\mathrm{BC}$ depolarization triggered at light offset by glutamate release from cones (Xu and Karwoski, 1995; Awatramani et al., 2001). Because the b-wave typically obscures the d-wave after shorter flashes, we bathed the eyecup in $10 \mu \mathrm{M}$ of the mGluR6 agonist L-AP4 to block the b-wave and isolate the d-wave. In the presence of L-AP4 alone, the d-wave increased in amplitude as the duration of the flash increased from $100 \mathrm{~ms}$ to $10 \mathrm{~s}$. In the presence of $20 \mu \mathrm{M}$ calmidazolium, the d-wave amplitude was reduced, especially after shorter flashes.

We performed similar flash-duration experiments while recording light responses of individual Off BCs and $\mathrm{HCs}$ in a retinal slice preparation (Fig. 7, C-F). In both Off BCs and HCs, the charge transfer during the fast inward current at light offset increased in amplitude with increasing flash duration, similar to previous work (Jackman et al., 2009). In the presence of $20 \mu \mathrm{M}$ calmidazolium, these responses were reduced, especially at shorter flash durations.

As a control, we tested for a role of $\mathrm{CaM}$ in modulating cone phototransduction by measuring light responses of individual cones using perforated patch current clamp recordings and found that they were unaffected by the addition of calmidazolium (Fig. S3). Calmidazolium also had no effect on the ERG a-wave (Fig. S4). This is consistent with other work indicating that although rod phototransduction can be modulated by CaM, the same is not true for cones (Haynes and Stotz, 1997). Together with the finding that calmidazolium had no effect on AMPA receptor currents (Fig. 3), this indicates that the effect of calmidazolium on Off $\mathrm{BC}$ and $\mathrm{HC}$ light responses is presynaptic rather than postsynaptic.

We also performed "simulated light flash" experiments (Jackman et al., 2009) using paired recordings of cones and HCs in which the cone was dialyzed with either the MLCK-control or MLCK peptide $(20 \mu \mathrm{M}$; Fig. 8). In these experiments, the cone was held at $-35 \mathrm{mV}$ before being stepped to $-70 \mathrm{mV}$ for a variable period of time ( $200 \mathrm{~ms}$ to $10 \mathrm{~s}$ ) to simulate the response to a bright light flash. The cone was then depolarized to $-10 \mathrm{mV}$ for $25 \mathrm{~ms}$ to trigger release of the entire IRP. In the presence of the MLCK-control peptide (Fig. 8 A, left), the response amplitude increased with increasing time spent at $-70 \mathrm{mV}$. With the MLCK peptide (Fig. $8 \mathrm{~A}$, right), the recovery of the response was slowed. With the MLCK-control peptide, the response recovered $75 \pm$ $5 \%$ (normalized to the response at $10 \mathrm{~s} ; n=7$ ) after $2 \mathrm{~s}$ at $-70 \mathrm{mV}$. With the MLCK peptide, the response recovered to only $41 \pm 6 \%$ (normalized to the response at $10 \mathrm{~s} ; n=6 ; \mathrm{P}=0.0017$ ) after $2 \mathrm{~s}$ at $-70 \mathrm{mV}$. These results indicate that $\mathrm{Ca}^{2+} / \mathrm{CaM}$-dependent rapid replenishment is important in allowing cones to transmit information about rapidly changing lighting conditions to second-order retinal neurons.
To further examine the role of CaM-dependent rapid replenishment in setting the temporal filtering properties cone synaptic transmission, we next recorded responses of second-order neurons to sinusoidal light stimuli (0.5-10 Hz; Fig. 9, A-C). If CaM-dependent rapid replenishment is important in setting the low-pass filter of cone synaptic transmission, we hypothesized that inhibiting CaM would affect both off-responding and on-responding retinal pathways. Therefore, we recorded from HCs as well as On BCs.

In control conditions, responses to a sinusoidal light stimulus peaked at $1.2 \pm 0.3 \mathrm{~Hz}$ for $\mathrm{HCs}(n=7)$ and $1.9 \pm 0.3$
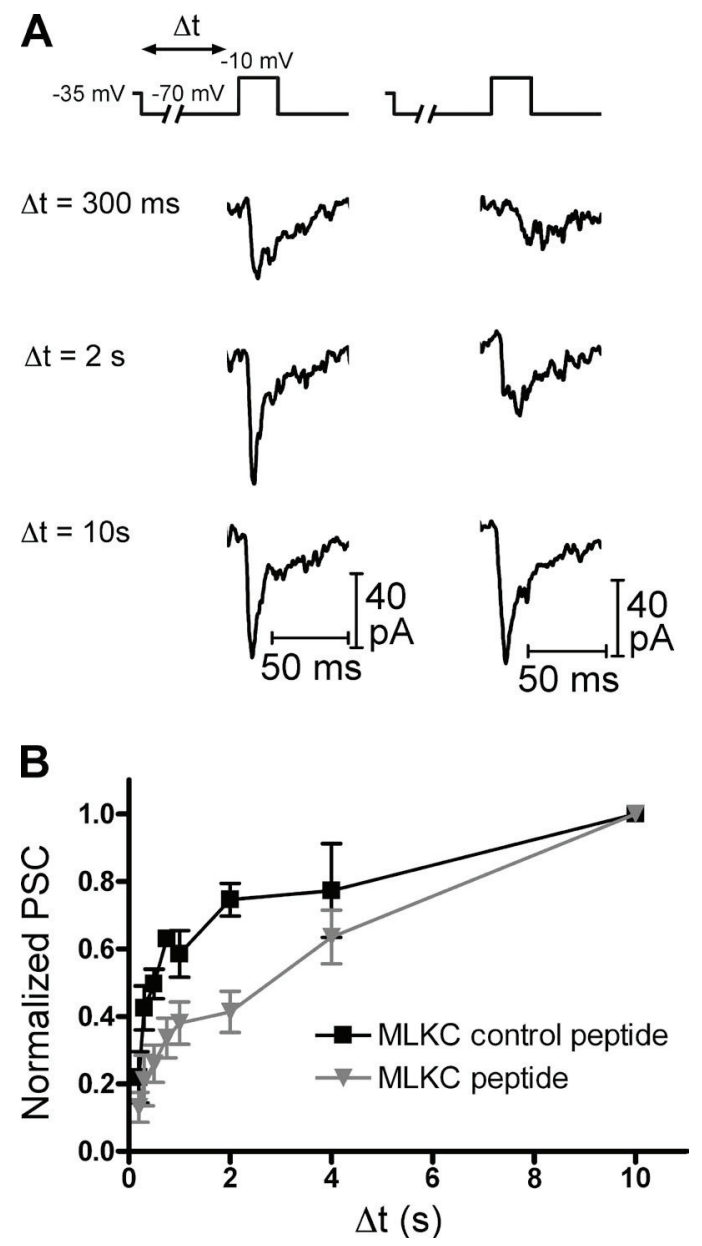

Figure 8. Simulated light flash experiments. (A) A light flash was mimicked in paired recordings of cones and HCs. The cone was voltage-clamped at $-35 \mathrm{mV}$ to mimic the dark potential and hyperpolarized to $-70 \mathrm{mV}$ for a variable duration $(\Delta t)$ to mimic a strong light flash before being depolarized to $-10 \mathrm{mV}$ (25 ms) to deplete the rapidly releasing vesicle pool. Cones were dialyzed with pipette solutions containing either the MLCK-control $(20 \mu \mathrm{M}$, left) or MLCK $(20 \mu \mathrm{M}$, right) peptide. (B) When cones were dialyzed with the MLCK-control peptide, the EPSC amplitude increased with increasing $\Delta t$. The amplitude of the EPSC was reduced when cones were instead dialyzed with the MLCK peptide. EPSC amplitude was normalized to the EPSC after the 10-s duration step. Mean \pm SEM is shown. 
$\mathrm{Hz}$ for On BCs $(n=7)$ and fell off at both higher and lower frequencies, consistent with band-pass properties of photoreceptor synaptic transmission in amphibian retinas (Fig. 9, B and C, black; Armstrong-Gold and Rieke, 2003; Burkhardt et al., 2007). In the presence of $20 \mu \mathrm{M}$ calmidazolium, responses for all HCs and On BCs peaked at $0.5 \mathrm{~Hz}$, the lowest frequency tested, and were reduced at higher frequencies relative to control conditions (Fig. 9, B and C, gray). To quantify this effect, we measured the frequency of $50 \%$ attenuation $\left(f_{50}\right)$. In control conditions, the $f_{50}$ was $2.8 \pm 0.2 \mathrm{~Hz}(n=7)$ and $3.7 \pm 0.2 \mathrm{~Hz}(n=7)$ for HCs and On BCs, respectively. In the presence of calmidazolium, the responses were shifted to lower frequencies so that the $f_{50}$ was $2.0 \pm 0.2 \mathrm{~Hz}(n=9 ; \mathrm{P}=0.005)$ and $2.6 \pm 0.2 \mathrm{~Hz}(n=5$; $\mathrm{P}=0.002$ ) for HCs and On BCs, respectively (Fig. 9, B and C). The similar effects of calmidazolium on both HCs and On BCs, which use different types of postsynaptic glutamate receptors, suggest that these effects are mediated by a common presynaptic target.
We noted above that calmidazolium does not affect cone responses to flashes of light. We also compared cone responses to sinusoidal light in the presence and absence of calmidazolium, finding that responses were unaffected (Fig. 9, D and E). This indicates that effects of calmidazolium on HC and On BC responses to sinusoidal stimuli were not the result of actions on the ability of the cone phototransduction cascade to follow a sinusoidal light stimulus.

We also performed experiments in which we stimulated cones with a sinusoidal voltage clamp command $(0.5-10 \mathrm{~Hz},-50$ to $-30 \mathrm{mV})$ while recording postsynaptic responses in HCs (Fig. $9 \mathrm{~F}$ ). When we dialyzed cones with $20 \mu \mathrm{M}$ MLCK-control peptide, the HC responses were band pass, with a peak at $3.0 \pm 0.3 \mathrm{~Hz}$, consistent with similar experiments in salamander rods (Armstrong-Gold and Rieke, 2003), and had an $f_{50}$ of $5.1 \pm 0.2 \mathrm{~Hz}(n=8)$. When cones were dialyzed with $20 \mu \mathrm{M}$ MLCK peptide, responses were shifted to lower frequencies, peaking at $1.7 \pm 0.2 \mathrm{~Hz}(\mathrm{P}=0.002)$ and having

\section{A Horizontal cell light responses}

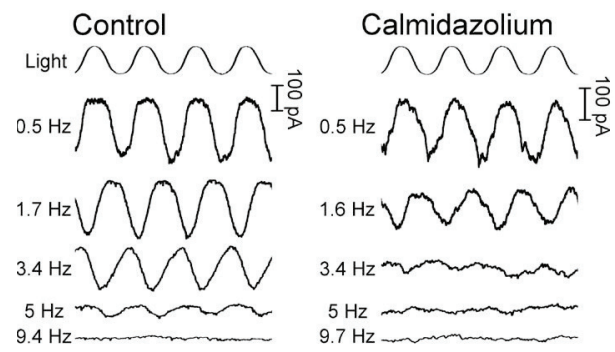

D Cone light responses

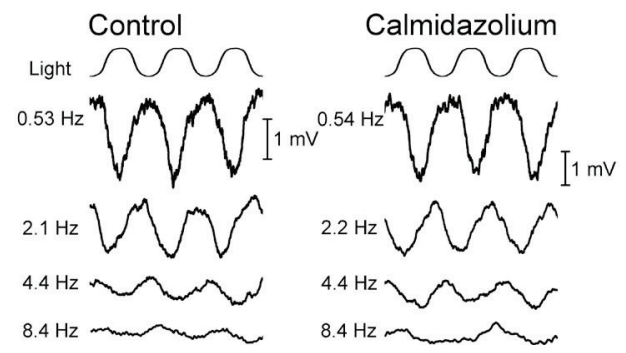

B Horizontal Cells

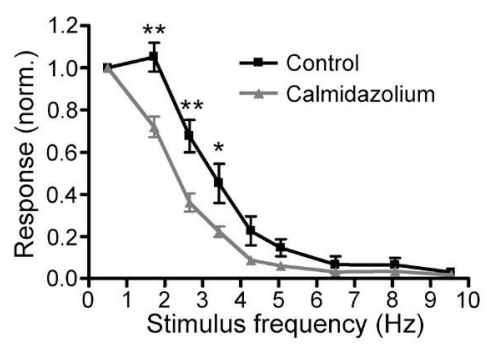

E Cones

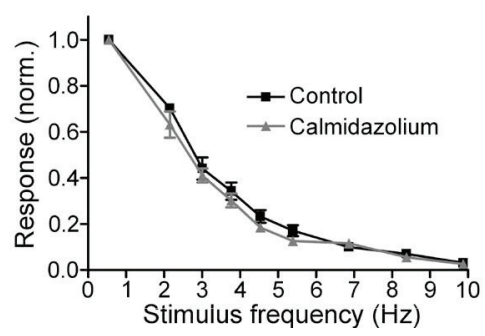

C On Bipolar Cells

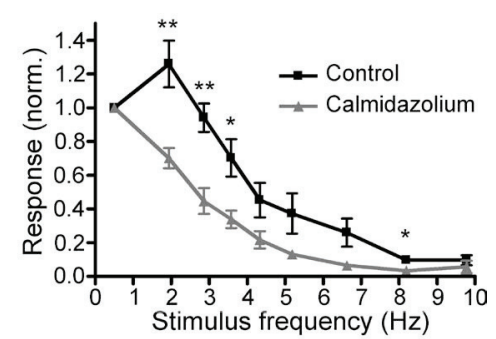

F Paired recordings

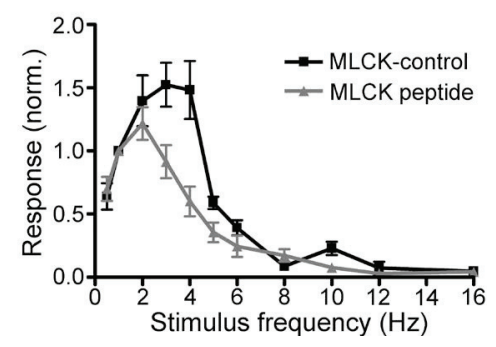

Figure 9. Synaptic responses to sinusoidal stimuli are reduced by inhibition of CaM. (A) In control voltage-clamp recordings of an HC (left), response amplitude to a sinusoidal light stimulus decreased with increasing stimulus frequency. In recordings from a different HC (right), response amplitude in the presence of $20 \mu \mathrm{M}$ calmidazolium declined at lower frequencies relative to control recordings. (B) HC group data normalized to the response amplitude at $0.5 \mathrm{~Hz}$. In the presence of calmidazolium, responses fell off at lower frequencies than in controls. (C) A similar effect was seen in recordings from On BCs. (D) Perforated patch current-clamp recordings of responses from two separate cones to sinusoidal light stimuli in control conditions (left) and in the presence of the CaM inhibitor calmidazolium ( $20 \mu \mathrm{M}$; right). (E) Under control conditions, the cone light responses were exclusively low pass, peaking at the lowest frequency tested $(0.5 \mathrm{~Hz})$ and falling off at higher frequencies. In the presence of calmidazolium, the responses were no different than in control conditions. (F) In paired recordings of cones and HCs, cones were stimulated with a $0.5-16-\mathrm{Hz}$ sinusoidal voltage-clamp command ( $20 \mathrm{mV}$ peak-to-peak around a holding potential of $-40 \mathrm{mV}$ ). Data were normalized to responses at $1 \mathrm{~Hz}$. When cones were dialyzed with the MLCK-control peptide $(20 \mu \mathrm{M} ; n=8)$, HC responses were band-pass, peaking at 3-4 Hz and falling off at higher or lower frequencies. When cones were dialyzed with the MLCK peptide (gray; $20 \mu \mathrm{M}$ ), response amplitude fell off at lower frequencies than in controls. Mean \pm SEM is shown. *, $\mathrm{P}<0.05$; **, $\mathrm{P}<0.01$. 
an $f_{50}$ of $4.0 \pm 0.3(n=7 ; \mathrm{P}=0.007)$. These data are consistent with a role for $\mathrm{Ca}^{2+} / \mathrm{CaM}$-dependent acceleration of ribbon replenishment in setting the frequency range over which the cone synapse can signal to downstream neurons in the visual pathway.

\section{DISCUSSION}

The results of this study shed light on the mechanisms used by cone synaptic ribbons to encode and transmit information to downstream neurons in the visual system. Sustained release is governed by the rate of replenishment (Jackman et al., 2009). Replenishment of cone ribbons is in turn $\mathrm{Ca}^{2+}$ dependent (Babai et al., 2010), and we used several approaches to probe the underlying mechanisms. Monitoring recovery from synaptic depression with a paired pulse stimulation protocol, we found that replenishment proceeds by fast ( $\tau \sim 800 \mathrm{~ms}$ ) and slow $(\tau \sim 13 \mathrm{~s})$ mechanisms and that the proportion of replenishment mediated by the fast process could be altered by manipulating intraterminal $\left[\mathrm{Ca}^{2+}\right]$. Inhibition of CaM slowed replenishment in cones, but mechanisms appear to differ from those that enhance replenishment at the calyx of Held (Sakaba and Neher, 2001). Although the occupancy state of the ribbon regulates replenishment rates with longer intervals and lower frequencies (Babai et al., 2010; Oesch and Diamond,
2011), inhibition of CaM revealed that $\mathrm{Ca}^{2+}$-dependent fast replenishment improves the ability of ribbon synapses to transmit high temporal frequency information.

\section{Mechanisms of CaM effects on replenishment}

By what mechanism does $\mathrm{Ca}^{2+} / \mathrm{CaM}$ accelerate replenishment in cones? We can eliminate several steps in the vesicle cycle as unlikely candidates because their kinetics cannot account for the rate of fast replenishment or they were unaffected by CaM inhibitors (Fig. 10). (a) Rapid endocytotic retrieval of vesicles by cones was not affected by CaM inhibitors, suggesting that neither insufficient vesicle supply nor impaired release site clearance is the origin of slowed replenishment. (b) Glutamate refilling of vesicles exhibits a time constant of 15 s (Hori and Takahashi, 2012), far slower than the fast component of replenishment $(\tau \sim 800 \mathrm{~ms})$. The reason that glutamate refilling does not normally become rate limiting is likely because of the large cytosolic reservoir pool that provides a substantial buffer of previously loaded vesicles; salamander cones contain 194,000 vesicles (Choi et al., 2005), with $85 \%$ participating in vesicle cycling (Rea et al., 2004; M. Chen et al., 2013). (c) CaM inhibitors did not alter the slower, second kinetic component of release, which represents release of vesicles after their descent down the ribbon (Bartoletti et al., 2010), indicating that $\mathrm{Ca}^{2+} / \mathrm{CaM}$ are unlikely to

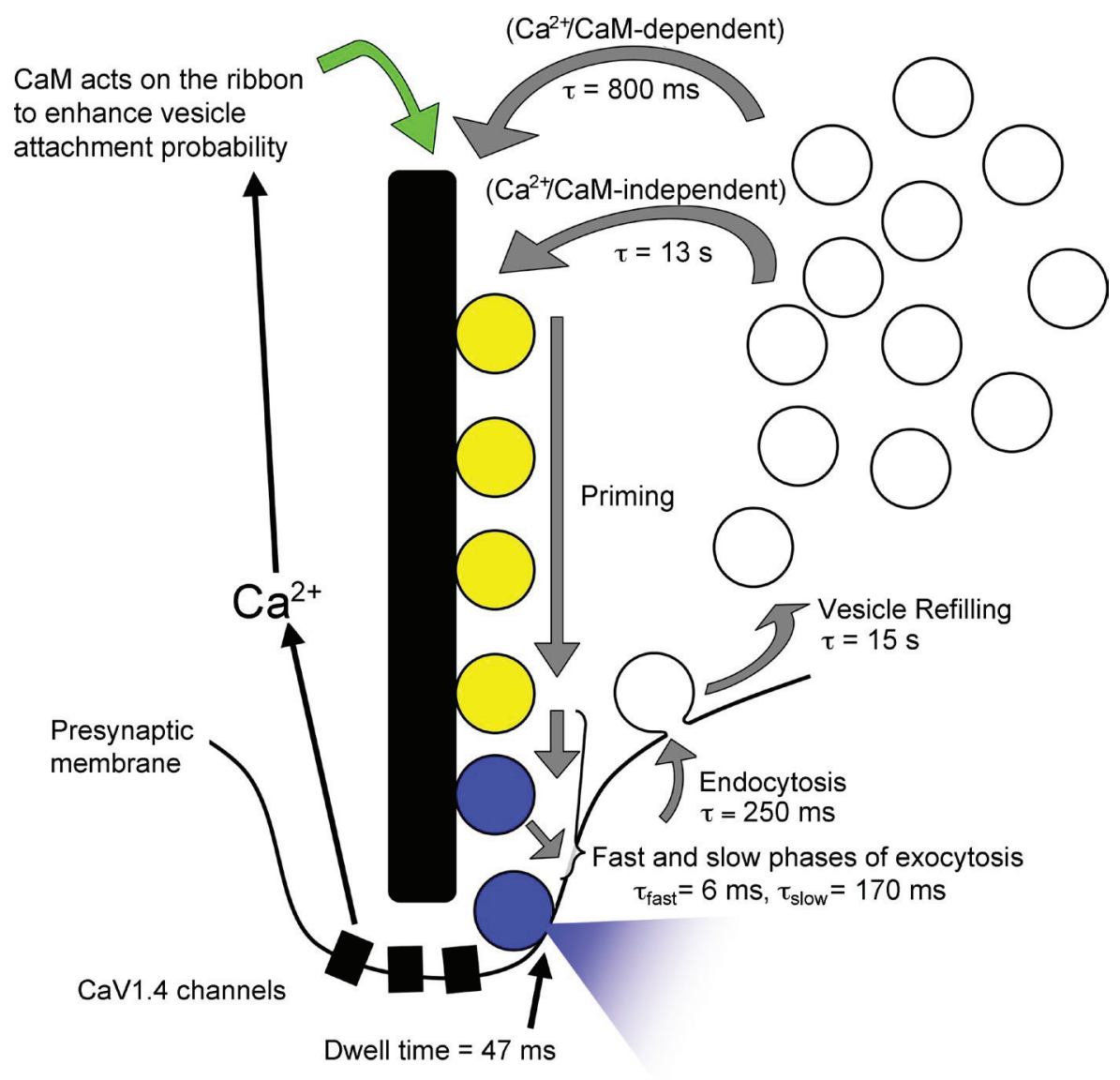

Figure 10. Proposed vesicle cycle at the cone ribbon synapse. Vesicles can be resupplied to the synaptic ribbon through a fast mechanism $(\tau \sim 800 \mathrm{~ms})$ that is regulated by the actions of $\mathrm{Ca}^{2+}$ / $\mathrm{CaM}$ on vesicle attachment sites on the ribbon, several hundred nanometers distant from $\mathrm{Ca}^{2+}$ entry through channels located at the ribbon base. Vesicles can also attach through a slower, $\mathrm{Ca}^{2+}$ / CaM-independent process that has a time constant of $\sim 13$ s. Vesicle priming appears to involve the synaptic ribbon (Snellman et al., 2011). Exocytosis occurs in two phases, with time constants of $6 \mathrm{~ms}$ and $170 \mathrm{~ms}$ that represent fast fusion of the IRP (blue) and movement of vesicles from the ribbon-associated reserve pool (yellow) to release sites near the ribbon base, respectively. Endocytosis is fast ( $\tau=250 \mathrm{~ms}$; Van Hook and Thoreson, 2012) and returns vesicles to a cytoplasmic reservoir pool, where they are refilled with glutamate $(\tau \sim 15 \mathrm{~s}$; Hori and Takahashi, 2012). 
accelerate replenishment by quickening the transition of vesicles to release sites at the ribbon base. (d) Vesicles spend only $\sim 47 \mathrm{~ms}$ at the membrane surface before fusion (membrane dwell time; Fig. S2), far shorter than the time constant for replenishment. (e) Fusion of vesicles in the IRP is much faster $(\tau \sim 6 \mathrm{~ms}$; Thoreson et al., 2004; Rabl et al., 2005; Bartoletti et al., 2010) than replenishment, and this fast component of release was not affected by CaM inhibition. These considerations leave only two steps as likely to be $\mathrm{Ca}^{2+}$ dependent and rate limiting for vesicle replenishment: (1) the time required for priming of newly attached vesicles by the ribbon and (2) the rate of vesicle attachment to the ribbon.

Our analytical model of vesicle resupply revealed that the kinetics of vesicle collisions with attachment sites is constrained by a fundamental time constant that depends on the diameter, density, and diffusion coefficient of vesicles. Using empirically determined parameters for cone synapses, the model predicted that if each vesicle that randomly collides with the ribbon is added to the ribbon pool, the time constant for replenishment would be $\sim 90 \mathrm{~ms}$, nearly 10 -fold faster than the measured time constant. Other factors such as vesicle descent down the ribbon may contribute to slower kinetics of replenishment, but if vesicle delivery to the ribbon is the rate-limiting step in replenishment, then this suggests that the probability of a single vesicle attaching to the ribbon upon collision is likely to be significantly $<1$. Although we used vesicle density measurements from salamander cones (Sheng et al., 2007), vesicles appear less concentrated in mouse rod terminals, $580-750 \mathrm{v} / \mu^{3}$ (Zampighi et al., 2011), implying there may be cell-tocell or species-to-species differences in the kinetics of vesicle resupply.

We developed two variations of the model to test possible sites of $\mathrm{Ca}^{2+} / \mathrm{CaM}$ regulation of replenishment. In model $1, \mathrm{Ca}^{2+} / \mathrm{CaM}$ acts on individual vesicles to increase the probability that they will attach to the ribbon, whereas in model 2, the loci for $\mathrm{Ca}^{2+} / \mathrm{CaM}$ action are the vesicle attachment sites on the ribbon. If, as in model 1, we assume that $\mathrm{Ca}^{2+} / \mathrm{CaM}$ acts on vesicles to enhance attachment probability, shifting the fraction of vesicles from a low- to a high-attachment probability population, then the overall attachment probability is simply a weighted mean of individual vesicle attachment probabilities. This yields a single time constant that quickens as more vesicles are added to the highprobability population and slows as more are added to the low-probability population. If, however, $\mathrm{Ca}^{2+} / \mathrm{CaM}$ acts on ribbon sites to enhance vesicle attachment, as in model 2, then the model yields two time constants. Thus, the predicted number of vesicles that have attached to the ribbon at a given time point is the sum of two terms, each with its own time constant. Furthermore, model 2 predicts that inhibiting $\mathrm{Ca}^{2+} / \mathrm{CaM}$ effects on vesicle attachment would slow replenishment by reducing the amplitude of the fast component, essentially reducing the number of ribbon sites with a higher attachment probability, but leaving the time constants unaltered. Our data lend greater support to model 2 for two reasons. First, the existence of a double exponential time course for recovery from synaptic depression is consistent with the existence of two populations of attachment sites on the ribbon. Second, the principal effect of inhibiting $\mathrm{Ca}^{2+} / \mathrm{CaM}$ on the time course of recovery was to reduce the amplitude carried by the fast time constant, consistent with model 2's predicted effects of reducing the number of high-attachment probability sites on the ribbon.

Synaptic ribbons are thought to serve as sites for vesicle priming (Snellman et al., 2011). Thus, another possible explanation for our data is that $\mathrm{Ca}^{2+} / \mathrm{CaM}$ catalyzes the priming of ribbon-associated vesicles, readying them for release more quickly than if they were primed by a $\mathrm{Ca}^{2+} / \mathrm{CaM}$-independent mechanism. However, actions of $\mathrm{Ca}^{2+} / \mathrm{CaM}$ on priming would only speed replenishment if the time required for priming was rate limiting for replenishment, i.e., if it exceeded the time needed for vesicles to attach, descend to the bottom of the ribbon, and dock at the membrane. Although actions on vesicle priming by the ribbon remain a possibility, the good agreement between model predictions and experimental results supports the hypothesis that $\mathrm{Ca}^{2+} / \mathrm{CaM}$ enhances replenishment by altering attachment probability of vesicle sites along the ribbon. This hypothesis is also supported by findings that $\mathrm{Ca}^{2+}$ accelerates replenishment by acting at sites $\sim 200-300 \mathrm{~nm}$ away from the $\mathrm{Ca}^{2+}$ entry sites (Babai et al., 2010), consistent with the synaptic ribbon being the locus of $\mathrm{Ca}^{2+}$ effects on replenishment.

\section{Potential molecular mechanisms of $\mathrm{Ca}^{2+} / \mathrm{CaM}$ effects}

There are several possible molecular mechanisms by which $\mathrm{Ca}^{2+} / \mathrm{CaM}$ might enhance replenishment in cones. CaM regulates vesicle priming, recruitment, and short-term plasticity by interactions with Munc13 (Junge et al., 2004; Zikich et al., 2008; Rodríguez-Castañeda et al., 2010; Lipstein et al., 2012), which is responsible for $\mathrm{Ca}^{2+} / \mathrm{CaM}$-dependent replenishment at the calyx of Held (Lipstein et al., 2013). However, deletion of Munc13 in photoreceptors had no effect on vesicle tethering to the ribbon and only modest effects on synaptic transmission measured with ERG recordings (Cooper et al., 2012), pointing toward a limited involvement of Munc13 in vesicle replenishment in photoreceptors. Synaptotagmin (syt) 7 complexes with CaM to accelerate replenishment in hippocampal neurons (Liu et al., 2014), but there is no evidence for syt 7 at retinal ribbon synapses (Kantardzhieva et al., 2012). Another potential CaM target is Rab3a, a vesicle-associated protein involved in both long- and short-term plasticity (Castillo et al., 1997; Geppert et al., 1997; Nonet et al., 1997; Leenders et al., 2001; Schlüter et al., 2004, 2006; 
Coleman et al., 2007), which is also required for delivery of functional vesicles to rod and cone ribbons (Tian et al., 2012). However, the fact that our data and predictions from the model suggest that $\mathrm{Ca}^{2+} / \mathrm{CaM}$ acts on ribbon sites rather than vesicles makes Rab3a an unlikely mediator of CaM effects in cones.

A more promising possible CaM target is the $\mathrm{Ca}^{2+}$ / CaM-dependent protein kinase, CaMKII, which associates with synaptic ribbons in hair cells and retinal neurons (Uthaiah and Hudspeth, 2010; Kantardzhieva et al., 2012) and is a well-established regulator of neurotransmitter release (Llinás et al., 1985; Nichols et al., 1990; Hinds et al., 2003; Pang et al., 2010). Dialysis of cones with a CaMKII inhibitor has similar effects to CaM inhibitors (unpublished data), making it a likely mediator of the CaM effects on vesicle replenishment of cone ribbons. In some synapses, CaMKII can facilitate L-type $I_{\mathrm{Ca}}$ (Hudmon et al., 2005; Blaich et al., 2010; Jenkins et al., 2010), and changes in $\mathrm{Ca}^{2+}$ influx can contribute to short-term synaptic depression (Forsythe et al., 1998). CaMKII can also regulate release by interacting with and/or phosphorylating other presynaptic proteins such as synapsin and rabphilin (Llinás et al., 1985; Benfenati et al., 1992; Mizoguchi et al., 1994; Nayak et al., 1996; Hilfiker et al., 1999a; Schlüter et al., 2006; Sun et al., 2006). However, both are reportedly absent from photoreceptor synapses (Mandell et al., 1990; Von Kriegstein et al., 1999). Other known targets of CaMKII, such as the vesicle-associated proteins PICK-1, synaptophysin, synaptobrevin, synaptotagmin, and membrane-associated syntaxin (Benfenati et al., 1992; Rubenstein et al., 1993; Nielander et al., 1995; Hilfiker et al., 1999a, b; Risinger and Bennett, 1999; Verona et al., 2000; Kim et al., 2002; Ohyama et al., 2002), might also underlie the effects of vesicle replenishment in cones. CaMKII might also act to phosphorylate other ribbon-specific proteins, such as RIBEYE or piccolino (Regus-Leidig et al., 2013), to regulate vesicle attachment probability.

\section{Comparisons with other synapses}

A double exponential process appears to be a common feature of recovery from synaptic depression at both ribbon and nonribbon synapses (Gomis et al., 1999; Sakaba and Neher, 2001; Singer and Diamond, 2006; Cho et al., 2011) and $\mathrm{Ca}^{2+}$ plays an important role in regulating such short-term plasticity at both synapse types (Mennerick and Matthews, 1996; Dittman and Regehr, 1998; Stevens and Wesseling, 1998; Wang and Kaczmarek, 1998; Gomis et al., 1999; Sakaba and Neher, 2001; Kuromi and Kidokoro, 2002; Singer and Diamond, 2006; Johnson et al., 2008; Babai et al., 2010; Cho et al., 2011). In goldfish BCs, recovery from synaptic depression is $\mathrm{Ca}^{2+}$ dependent (Gomis et al., 1999) and proceeds by two time constants with $\tau_{\text {fast }}=0.6-1 \mathrm{~s}$ and $\tau_{\text {slow }}=$ 12-30 s (Gomis et al., 1999; Palmer et al., 2003), very similar to our findings in salamander cones. Recovery is slightly faster in mammalian RBCs, where $\tau_{\text {fast }}=400 \mathrm{~ms}$ and $\tau_{\text {slow }}=5.9 \mathrm{~s}$, measured at room temperature (Singer and Diamond, 2006). Recovery is likely to be faster in vivo because the rate of vesicle recruitment at the calyx of Held synapse is enhanced at physiological temperatures (Kushmerick et al., 2006). Physiological temperatures can influence the timing of $\mathrm{Ca}^{2+}$ entry, quickening $I_{\mathrm{Ca}}$ activation and enhancing inactivation (Kushmerick et al., 2006). Although these two opposing effects ultimately leave the total $\mathrm{Ca}^{2+}$ charge transfer unchanged at the calyx of Held (Kushmerick et al., 2006), the altered timing of the $\mathrm{Ca}^{2+}$ signal might contribute $\mathrm{Ca}^{2+}$-dependent recruitment of vesicles at physiological temperatures. In slices from goldfish retinas with low extracellular $\mathrm{pH}$ buffering, quickened recovery from synaptic depression is the result of reduced exocytosis during the first of a pair of depolarizing pulses (Palmer et al., 2003). This is caused by proton-mediated inhibition of terminal $I_{\mathrm{Ca}}$ and relief of $I_{\mathrm{Ca}}$ inhibition that leads to greater exocytosis on subsequent pulses (Palmer et al., 2003). Although we show that $I_{\mathrm{Ca}}$ also facilitates in cones, this appears not to be the origin of the $\mathrm{Ca}^{2+}$ / CaM-dependent recovery process we describe here, as $I_{\mathrm{Ca}}$ facilitation is unperturbed by the CaM inhibitors that slow recovery. However, because protons play a key role in regulating photoreceptor $I_{\mathrm{Ca}}$ (DeVries 2001; Hirasawa and Kaneko, 2003), a similar mechanism may contribute to recovery from synaptic depression under conditions with reduced extracellular $\mathrm{pH}$ buffering, e.g., with a bicarbonate-based saline solution. In hair cells, although synaptic transmission facilitates when resting intracellular $\left[\mathrm{Ca}^{2+}\right]$ is reduced with a hyperpolarized holding potential, depression dominates at physiological resting potentials (Cho et al., 2011). In this case, the recovery from synaptic depression is strikingly fast, with time constants of 15 and $581 \mathrm{~ms}$ (Cho et al., 2011).

Our analytical model can be readily applied to other ribbon-type synapses. Thus, for example, taking $s=1$ at synapses where the diffusion coefficient, vesicle density, and vesicle diameters are known, the time constant

$$
\tau_{a}=\frac{1}{D \rho \delta s}
$$

can be used to predict the expected kinetics of vesicle resupply to the ribbon caused by vesicle collisions. In goldfish BCs, $D=0.015 \mu^{2} / \mathrm{s}$ (Holt et al., 2004) and $\delta=30 \mathrm{~nm}$ (Paillart et al., 2003). The density of cytoplasmic vesicles near the ribbon is $524 \mathrm{v} / \mu^{3}{ }^{3}$, but some of these are immobile (Holt et al., 2004). If $85 \%$ are mobile (Rea et al., 2004), this yields $\rho=445 \mathrm{v} / \mu^{3}$. Together, these values predict $\tau_{a}=5 \mathrm{~s}$. This is very close to the measured time constant of replenishment obtained by paired pulse protocols $(\tau=4 \mathrm{~s}$; Mennerick and Matthews, 1996), suggesting that vesicle collisions may limit the 
rate of replenishment and thus sustained release. These findings are also roughly consistent with calculations by Holt et al. (2004), who predicted a rate of 1 collision per attachment site every $2.8 \mathrm{~s}$. Slightly faster values for replenishment time constants at BCs have also been reported (Gomis et al., 1999; Palmer et al., 2003). In RBCs, measurements of $\delta=38 \mathrm{~nm}$ and $\rho=1933 \mathrm{v} / \mu^{3}{ }^{3}$ (Graydon et al., 2014), used with $D=0.015 \mathrm{\mu m}^{2} / \mathrm{s}$ from goldfish BCs (Holt et al., 2004), give a predicted replenishment time constant of $908 \mathrm{~ms}$, which is slower than the measured fast kinetic component of recovery from paired pulse protocols ( $\tau=400 \mathrm{~ms}$; Singer and Diamond, 2006).

In hair cells, as noted above, recovery from synaptic depression is exceptionally fast, with time constants of 15 and $581 \mathrm{~ms}$ (Cho et al., 2011). Interestingly, using a similar approach to ours to model vesicle collisions with the ribbon in hair cells, Graydon et al. (2011) found that the collision rate was too slow $(\sim 24 \mathrm{v} / \mathrm{s} /$ ribbon $)$ to account for the measured sustained release rate $(53 \mathrm{v} / \mathrm{s} /$ ribbon) and proposed that an active ATP- and/or $\mathrm{Ca}^{2+}$ dependent process might compensate for this by increasing vesicle mobility. Using values of vesicle density, diameter, and diffusion coefficient used by the authors $\left(\rho=851 \mathrm{v} / \mu \mathrm{m}^{3}, \delta=32.9 \mathrm{~nm}\right.$, and $D=0.015 \mu^{2} / \mathrm{s} ;$ Holt et al., 2004; Graydon et al., 2011), we find a predicted replenishment time constant of $2.4 \mathrm{~s}$, which is much slower than the measured value. However, the authors used a diffusion coefficient measured in fish BCs $\left(0.015 \mathrm{\mu m}^{2} / \mathrm{s}\right.$; Holt, et al., 2004), which might be an underestimate of the actual value in hair cells. Using the faster diffusion coefficient from cone photoreceptors $\left(0.11 \mu \mathrm{m}^{2} / \mathrm{s}\right.$; Rea et al., 2004) gives a collision rate of $173 \mathrm{v} / \mathrm{s} /$ ribbon, which is fast enough to account for the hit rate. Likewise, using the faster diffusion coefficient gives a predicted replenishment time constant of $325 \mathrm{~ms}$, which is closer to the measured second time constant in hair cells ( $~ 580 \mathrm{~ms}$; Cho et al., 2011).

Although the formula used by Graydon et al. (2011) calculates the rate of vesicle collisions with a spherical ribbon to estimate sustained release rate, ours was derived with the intention of modeling the time constant underlying the replenishment process and is therefore independent of ribbon size. However, we estimated the hit rate of vesicles with a cone ribbon by deriving a formula analogous to that used by Graydon et al. (2011) and calculated a predicted hit rate of $\sim 1,200 \mathrm{v} / \mathrm{s} /$ ribbon. This is considerably faster than the sustained release rates measured from depolarizing pulse trains in cones $(\sim 300 \mathrm{v} / \mathrm{s} /$ ribbon, above $)$, consistent with the predicted replenishment time constant $\left(\tau_{a}=91 \mathrm{~ms}\right)$, which is also faster than the measured value $(815 \mathrm{~ms})$. This indicates that vesicle collisions are sufficiently fast to support both the measured replenishment and sustained release rates in cones. Replenishment of the cone ribbon would therefore not require the enhancement of vesicle mobility proposed for hair cells (Graydon et al., 2011). Moreover, no such mechanism appears to operate in cones as fluorescence recovery after photobleaching measurements indicate that $\mathrm{Ca}^{2+}$ does not alter vesicle mobility (Rea et al., 2004). In TIRFM experiments in salamander rods, the velocity of vesicle approach to the presynaptic membrane in response to a depolarizing step was the same at nonribbon and ribbon-associated sites, at which $\left[\mathrm{Ca}^{2+}\right]$ reaches lower and higher levels, respectively (M. Chen et al., 2013), consistent with a lack of an effect of $\left[\mathrm{Ca}^{2+}\right]$ on vesicle mobility in photoreceptors. Likewise, $\mathrm{Ca}^{2+}$ also appears to have no effect on vesicle mobility in goldfish BCs (Holt et al., 2004).

Because our analytical model makes no assumptions about synaptic geometry except that vesicle attachment sites are accessible only from one side, it can be similarly used to understand factors affecting vesicle dynamics in nonribbon synapses. At hippocampal synapses, $D=0.0042 \mu \mathrm{m}^{2} / \mathrm{s}$ (Shtrahman et al., 2005) and $\delta=38 \mathrm{~nm}$ (Harris and Sultan, 1995). Vesicle density averages 1,800-3,100 v/ $\mu^{3}{ }^{3}$ (Harris and Stevens, 1989; Schikorski and Stevens, 1997), but only $15 \%$ are mobile (Shtrahman et al., 2005), yielding an effective range for $\rho$ of $270-465 \mathrm{v} / \mu^{3}$. From these values, the formula predicts a maximum kinetics of vesicle resupply from the cytoplasm of $\tau=13-23 \mathrm{~s}$. For comparison, replenishment at hippocampal synapses involves a fast process with $\tau \sim 7 \mathrm{~s}$ and a slower process with $\tau \sim 1 \mathrm{~min}$; the slower process is thought to reflect the kinetics of resupply to the readily releasable pool (Stevens and Wesseling, 1998; Wesseling and Lo, 2002; Garcia-Perez and Wesseling, 2008).

\section{Implications for visual processing}

Rod and cone light responses are filtered at the synapse, which, in amphibian retinas, optimally transmits responses at 1-4 Hz (Armstrong-Gold and Rieke, 2003; Burkhardt et al., 2007). Several pre- and postsynaptic mechanisms have been implicated in shaping frequency responses of photoreceptor synaptic transmission (Schnapf and Copenhagen, 1982; DeVries, 2000; Armstrong-Gold and Rieke, 2003; Zhang and Wu, 2005; Barrow and $\mathrm{Wu}, 2009)$. Synaptic vesicle depletion and the kinetics of resupply are known to influence filtering at other synapses (Dittman and Regehr, 1998; Fortune and Rose, 2001; Abbott and Regehr, 2004) and have been proposed as having a key role at photoreceptor synapses as well (Rabl et al., 2006; Burkhardt et al., 2007). In this study, the effects of CaM inhibition on replenishment provided a convenient means by which to test the functional role of fast replenishment in cone signaling. Inhibition of CaM reduced the ability of the synapse to transmit responses to higher-frequency stimuli, indicating that rapid replenishment, by quickening the resupply vesicles to the synaptic ribbon, extends the range of temporal frequencies over which the synapse operates.

Analysis of natural visual scenes shows that power falls off with increasing temporal frequency with a slope 
near that of a $1 / f$ power law (Dong and Atick, 1995; van Hateren, 1997). However, the temporal frequency of visual motion that is relevant for animal behavior, such as hunting prey, avoiding predators, or mating, likely does not match the distribution of temporal frequencies in natural scenes (Eckert and Zeil, 2001). Thus, bandpass filtering at the synapse might be adapted to boost encoding and transmission of real-world events occurring at behaviorally relevant temporal frequencies while removing behaviorally irrelevant information or environmental noise (Eckert and Zeil, 2001). Our findings indicate that the temporal response properties of the photoreceptor synapse, and consequently of the visual system, are shaped by the $\mathrm{Ca}^{2+} / \mathrm{CaM}$-dependent recruitment of a fast mechanism of vesicle resupply to the synaptic ribbon.

This paper was supported by National Institutes of Health grants EY10542 (to W.B. Thoreson) and F32EY023864 (to M.J. Van Hook), Research to Prevent Blindness (to W.B. Thoreson), and National Science Foundation grant DMS-1225666 (to C. Curto). Financial support from Fight for Sight is gratefully acknowledged (to M.J. Van Hook).

The authors declare no competing financial interests.

Angus C. Nairn served as editor.

Submitted: 13 May 2014

Accepted: 11 September 2014

\section{REFERENCES}

Abbott, L.F., and W.G. Regehr. 2004. Synaptic computation. Nature. 431:796-803. http://dx.doi.org/10.1038/nature03010

Armstrong-Gold, C.E., and F. Rieke. 2003. Bandpass filtering at the rod to second-order cell synapse in salamander (Ambystoma tigrinum) retina. J. Neurosci. 23:3796-3806.

Awatramani, G., J. Wang, and M.M. Slaughter. 2001. Amacrine and ganglion cell contributions to the electroretinogram in amphibian retina. Vis. Neurosci. 18:147-156. http://dx.doi.org/10.1017/ S0952523801181149

Babai, N., T.M. Bartoletti, and W.B. Thoreson. 2010. Calcium regulates vesicle replenishment at the cone ribbon synapse. J. Neurosci. 30:15866-15877. http://dx.doi.org/10.1523/ JNEUROSCI.2891-10.2010

Barrow, A.J., and S.M. Wu. 2009. Low-conductance HCN1 ion channels augment the frequency response of rod and cone photoreceptors. J. Neurosci. 29:5841-5853. http://dx.doi.org/10.1523/ JNEUROSCI.5746-08.2009

Bartoletti, T.M., N. Babai, and W.B. Thoreson. 2010. Vesicle pool size at the salamander cone ribbon synapse. J. Neurophysiol. 103:419-423. http://dx.doi.org/10.1152/jn.00718.2009

Bartoletti, T.M., S.L. Jackman, N. Babai, A.J. Mercer, R.H. Kramer, and W.B. Thoreson. 2011. Release from the cone ribbon synapse under bright light conditions can be controlled by the opening of only a few $\mathrm{Ca}^{2+}$ channels. J. Neurophysiol. 106:2922-2935. http://dx.doi .org/10.1152/jn.00634.2011

Benfenati, F., F. Valtorta, J.L. Rubenstein, F.S. Gorelick, P. Greengard, and A.J. Czernik. 1992. Synaptic vesicle-associated $\mathrm{Ca}^{2+} /$ calmodulin-dependent protein kinase II is a binding protein for synapsin I. Nature. 359:417-420. http://dx.doi.org/10.1038/359417a0
Berg, H.C. 1983. Random Walks in Biology. Princeton University Press, Princeton, N.J. 142 pp.

Blaich, A., A. Welling, S. Fischer, J.W. Wegener, K. Köstner, F. Hofmann, and S. Moosmang. 2010. Facilitation of murine cardiac L-type $\mathrm{Ca}_{\mathrm{v}} 1.2$ channel is modulated by calmodulin kinase II-dependent phosphorylation of S1512 and S1570. Proc. Natl. Acad. Sci. USA. 107:10285-10289. http://dx.doi.org/10.1073/pnas.0914287107

Burkhardt, D.A., P.K. Fahey, and M.A. Sikora. 2007. Retinal bipolar cells: temporal filtering of signals from cone photoreceptors. Vis. Neurosi. 24:765-774. http://dx.doi.org/10.1017/S0952523807070630

Cadetti, L., D. Tranchina, and W.B. Thoreson. 2005. A comparison of release kinetics and glutamate receptor properties in shaping rod-cone differences in EPSC kinetics in the salamander retina. J. Physiol. 569:773-788. http://dx.doi.org/10.1113/ jphysiol.2005.096545

Cadetti, L., T.M. Bartoletti, and W.B. Thoreson. 2008. Quantal mEPSCs and residual glutamate: how horizontal cell responses are shaped at the photoreceptor ribbon synapse. Eur. J. Neurosci. 27:2575-2586. http://dx.doi.org/10.1111/j.1460-9568.2008.06226.x

Castillo, P.E., R. Janz, T.C. Südhof, T. Tzounopoulos, R.C. Malenka, and R.A. Nicoll. 1997. Rab3A is essential for mossy fibre longterm potentiation in the hippocampus. Nature. 388:590-593. http://dx.doi.org/10.1038/41574

Chen, M., M.J. Van Hook, D. Zenisek, and W.B. Thoreson. 2013. Properties of ribbon and non-ribbon release from rod photoreceptors revealed by visualizing individual synaptic vesicles. $J$. Neurosci. 33:2071-2086. http://dx.doi.org/10.1523/JNEUROSCI .3426-12.2013

Chen, Z., B. Cooper, S. Kalla, F. Varoqueaux, and S.M. Young Jr. 2013. The Munc13 proteins differentially regulate readily releasable pool dynamics and calcium-dependent recovery at a central synapse. J. Neurosci. 33:8336-8351. http://dx.doi.org/10.1523/ JNEUROSCI.5128-12.2013

Cho, S., G.L. Li, and H. von Gersdorff. 2011. Recovery from shortterm depression and facilitation is ultrafast and $\mathrm{Ca}^{2+}$ dependent at auditory hair cell synapses. J. Neurosci. 31:5682-5692. http://dx .doi.org/10.1523/JNEUROSCI.5453-10.2011

Choi, S.-Y., B.G. Borghuis, R. Rea, E.S. Levitan, P. Sterling, and R.H. Kramer. 2005. Encoding light intensity by the cone photoreceptor synapse. Neuron. 48:555-562. (published erratum appears in Neuron. 2005. 48:1067) http://dx.doi.org/10.1016/ j.neuron.2005.09.011

Coleman, W.L., C.A. Bill, and M. Bykhovskaia. 2007. Rab3a deletion reduces vesicle docking and transmitter release at the mouse diaphragm synapse. Neuroscience. 148:1-6. http://dx.doi .org/10.1016/j.neuroscience.2007.06.011

Cooper, B., M. Hemmerlein, J. Ammermüller, C. Imig, K. Reim, N. Lipstein, S. Kalla, H. Kawabe, N. Brose, J.H. Brandstätter, and F. Varoqueaux. 2012. Munc13-independent vesicle priming at mouse photoreceptor ribbon synapses. J. Neurosci. 32:8040-8052. http://dx.doi.org/10.1523/JNEUROSCI.4240-11.2012

Derkach, V., A. Barria, and T.R. Soderling. 1999. $\mathrm{Ca}^{2+} /$ calmodulinkinase II enhances channel conductance of $\alpha$-amino-3-hydroxy5-methyl-4-isoxazolepropionate type glutamate receptors. Proc. Natl. Acad. Sci. USA. 96:3269-3274. http://dx.doi.org/10.1073/ pnas.96.6.3269

DeVries, S.H. 2000. Bipolar cells use kainate and AMPA receptors to filter visual information into separate channels. Neuron. 28:847-856. http://dx.doi.org/10.1016/S0896-6273(00)00158-6

DeVries, S.H. 2001. Exocytosed protons feedback to suppress the $\mathrm{Ca}^{2+}$ current in mammalian cone photoreceptors. Neuron. 32: 1107-1117. http://dx.doi.org/10.1016/S0896-6273(01)00535-9

Dittman, J.S., and W.G. Regehr. 1998. Calcium dependence and recovery kinetics of presynaptic depression at the climbing fiber to Purkinje cell synapse. J. Neurosci. 18:6147-6162. 
Dong, D.W., and J.J. Atick. 1995. Statistics of natural time-varying images. Network: Computation in Neural Systems. 6:345-358. http:// dx.doi.org/10.1088/0954-898X/6/3/003

Eckert, M.P., and J. Zeil. 2001. Towards an ecology of motion vision. In Motion Vision. J.M. Zanker, and J. Zeil, editors. SpringerVerlag, Berlin. 333-369.

Forsythe, I.D., T. Tsujimoto, M. Barnes-Davies, M.F. Cuttle, and T. Takahashi. 1998. Inactivation of presynaptic calcium current contributes to synaptic depression at a fast central synapse. Neuron. 20:797-807. http://dx.doi.org/10.1016/S0896-6273(00)81017-X

Fortune, E.S., and G.J. Rose. 2001. Short-term synaptic plasticity as a temporal filter. Trends Neurosci. 24:381-385. http://dx.doi.org/ 10.1016/S0166-2236(00)01835-X

Garcia-Perez, E., and J.F. Wesseling. 2008. Augmentation controls the fast rebound from depression at excitatory hippocampal synapses. J. Neurophysiol. 99:1770-1786. http://dx.doi.org/10.1152/ jn.01348.2007

Geppert, M., Y. Goda, C.F. Stevens, and T.C. Südhof. 1997. The small GTP-binding protein Rab3A regulates a late step in synaptic vesicle fusion. Nature. 387:810-814. http://dx.doi.org/10.1038/42954

Gomis, A., J. Burrone, and L. Lagnado. 1999. Two actions of calcium regulate the supply of releasable vesicles at the ribbon synapse of retinal bipolar cells. J. Neurosci. 19:6309-6317.

Graydon, C.W., S. Cho, G.L. Li, B. Kachar, and H. von Gersdorff. 2011. Sharp $\mathrm{Ca}^{2+}$ nanodomains beneath the ribbon promote highly synchronous multivesicular release at hair cell synapses. J. Neurosci. 31:16637-16650. http://dx.doi.org/10.1523/JNEUROSCI $.1866-11.2011$

Graydon, C.W., J. Zhang, N.W. Oesch, A.A. Sousa, R.D. Leapman, and J.S. Diamond. 2014. Passive diffusion as a mechanism underlying ribbon synapse vesicle release and resupply. J. Neurosci. 34:89488962. http://dx.doi.org/10.1523/JNEUROSCI.1022-14.2014

Griessmeier, K., H. Cuny, K. Rötzer, O. Griesbeck, H. Harz, M. Biel, and C. Wahl-Schott. 2009. Calmodulin is a functional regulator of Cav1.4 L-type Ca ${ }^{2+}$ channels. J. Biol. Chem. 284:29809-29816. http://dx.doi.org/10.1074/jbc.M109.048082

Harris, K.M., and J.K. Stevens. 1989. Dendritic spines of CA 1 pyramidal cells in the rat hippocampus: serial electron microscopy with reference to their biophysical characteristics. J. Neurosci. 9:2982-2997.

Harris, K.M., and P. Sultan. 1995. Variation in the number, location and size of synaptic vesicles provides an anatomical basis for the nonuniform probability of release at hippocampal CA1 synapses. Neuropharmacology. 34:1387-1395. http://dx.doi.org/10 .1016/0028-3908(95)00142-S

Hayashi, Y., S.H. Shi, J.A. Esteban, A. Piccini, J.C. Poncer, and R. Malinow. 2000. Driving AMPA receptors into synapses by LTP and CaMKII: requirement for GluR1 and PDZ domain interaction. Science. 287:2262-2267. http://dx.doi.org/10.1126/science .287 .5461 .2262

Haynes, L.W., and S.C. Stotz. 1997. Modulation of rod, but not cone, cGMP-gated photoreceptor channels by calcium-calmodulin. Vis. Neurosci. 14:233-239. http://dx.doi.org/10.1017/ S0952523800011378

Heidelberger, R., W.B. Thoreson, and P. Witkovsky. 2005. Synaptic transmission at retinal ribbon synapses. Prog. Retin. Eye Res. 24:682-720. http://dx.doi.org/10.1016/j.preteyeres.2005.04.002

Hilfiker, S., V.A. Pieribone, A.J. Czernik, H.-T. Kao, G.J. Augustine, and P. Greengard. 1999a. Synapsins as regulators of neurotransmitter release. Philos. Trans. R. Soc. Lond. B Biol. Sci. 354:269-279. http://dx.doi.org/10.1098/rstb.1999.0378

Hilfiker, S., V.A. Pieribone, C. Nordstedt, P. Greengard, and A.J. Czernik. 1999b. Regulation of synaptotagmin I phosphorylation by multiple protein kinases. J. Neurochem. 73:921-932. http:// dx.doi.org/10.1046/j.1471-4159.1999.0730921.x
Hinds, H.L., I. Goussakov, K. Nakazawa, S. Tonegawa, and V.Y. Bolshakov. 2003. Essential function of $\alpha$-calcium/calmodulindependent protein kinase II in neurotransmitter release at a glutamatergic central synapse. Proc. Natl. Acad. Sci. USA. 100: 4275-4280. http://dx.doi.org/10.1073/pnas.0530202100

Hirasawa, H., and A. Kaneko. 2003. pH changes in the invaginating synaptic cleft mediate feedback from horizontal cells to cone photoreceptors by modulating $\mathrm{Ca}^{2+}$ channels. J. Gen. Physiol. 122: 657-671. http://dx.doi.org/10.1085/jgp.200308863

Holt, M., A. Cooke, A. Neef, and L. Lagnado. 2004. High mobility of vesicles supports continuous exocytosis at a ribbon synapse. Curr. Biol. 14:173-183. http://dx.doi.org/10.1016/j.cub.2003.12.053

Hori, T., and T. Takahashi. 2012. Kinetics of synaptic vesicle refilling with neurotransmitter glutamate. Neuron. 76:511-517. http:// dx.doi.org/10.1016/j.neuron.2012.08.013

Hudmon, A., H. Schulman, J. Kim, J.M. Maltez, R.W. Tsien, and G.S. Pitt. 2005. CaMKII tethers to L-type $\mathrm{Ca}^{2+}$ channels, establishing a local and dedicated integrator of $\mathrm{Ca}^{2+}$ signals for facilitation. J. Cell Biol. 171:537-547. http://dx.doi.org/10.1083/jcb .200505155

Jackman, S.L., S.-Y. Choi, W.B. Thoreson, K. Rabl, T.M. Bartoletti, and R.H. Kramer. 2009. Role of the synaptic ribbon in transmitting the cone light response. Nat. Neurosci. 12:303-310. http:// dx.doi.org/10.1038/nn.2267

Jenkins, M.A., C.J. Christel, Y. Jiao, S. Abiria, K.Y. Kim, Y.M. Usachev, G.J. Obermair, R.J. Colbran, and A. Lee. 2010. $\mathrm{Ca}^{2+}$-dependent facilitation of Cav1.3 $\mathrm{Ca}^{2+}$ channels by densin and $\mathrm{Ca}^{2+} /$ calmodulindependent protein kinase II. J. Neurosci. 30:5125-5135. http:// dx.doi.org/10.1523/JNEUROSCI.4367-09.2010

Johnson, S.L., M.V. Thomas, and C.J. Kros. 2002. Membrane capacitance measurement using patch clamp with integrated selfbalancing lock-in amplifier. Pflugers Arch. 443:653-663. http:// dx.doi.org/10.1007/s00424-001-0763-z

Johnson, S.L., A. Forge, M. Knipper, S. Münkner, and W. Marcotti. 2008. Tonotopic variation in the calcium dependence of neurotransmitter release and vesicle pool replenishment at mammalian auditory ribbon synapses. J. Neurosci. 28:7670-7678. http:// dx.doi.org/10.1523/JNEUROSCI.0785-08.2008

Junge, H.J., J.-S. Rhee, O. Jahn, F. Varoqueaux, J. Spiess, M.N. Waxham, C. Rosenmund, and N. Brose. 2004. Calmodulin and Munc13 form a $\mathrm{Ca}^{2+}$ sensor/effector complex that controls shortterm synaptic plasticity. Cell. 118:389-401. http://dx.doi.org/10 $.1016 /$ j.cell.2004.06.029

Kantardzhieva, A., M. Peppi, W.S. Lane, and W.F. Sewell. 2012. Protein composition of immunoprecipitated synaptic ribbons. $J$. Proteome Res. 11:1163-1174. http://dx.doi.org/10.1021/pr2008972

Ke, J.-B., Y.V. Wang, B.G. Borghuis, M.S. Cembrowski, H. Riecke, W.L. Kath, J.B. Demb, and J.H. Singer. 2014. Adaptation to background light enables contrast coding at rod bipolar cell synapses. Neuron. 81:388-401. http://dx.doi.org/10.1016/j.neuron.2013.10.054

Kim, A.-R., W.-H. Choi, S.-R. Lee, J.-S. Kim, C.-Y. Jeon, J.-I. Kim, J. Kim, J.-Y. Lee, E.-G. Kim, and J.-B. Park. 2002. Phosphorylation of 46-kDa protein of synaptic vesicle membranes is stimulated by GTP and $\mathrm{Ca}^{2+} /$ calmodulin. Exp. Mol. Med. 34:434-443. http://dx.doi.org/ 10.1038/emm.2002.61

Kourennyi, D.E., and S. Barnes. 2000. Depolarization-induced calcium channel facilitation in rod photoreceptors is independent of G proteins and phosphorylation. J. Neurophysiol. 84:133-138.

Kuromi, H., and Y. Kidokoro. 2002. Selective replenishment of two vesicle pools depends on the source of $\mathrm{Ca}^{2+}$ at the Drosophila synapse. Neuron. 35:333-343. http://dx.doi.org/10.1016/S08966273(02) 00777-8

Kushmerick, C., R. Renden, and H. von Gersdorff. 2006. Physiological temperatures reduce the rate of vesicle pool depletion and short-term depression via an acceleration of vesicle recruitment. 
J. Neurosci. 26:1366-1377. http://dx.doi.org/10.1523/JNEUROSCI .3889-05.2006

Leenders, A.G., F.H. Lopes da Silva, W.E. Ghijsen, and M. Verhage. 2001. Rab3a is involved in transport of synaptic vesicles to the active zone in mouse brain nerve terminals. Mol. Biol. Cell. 12:3095-3102. http://dx.doi.org/10.1091/mbc.12.10.3095

Lipstein, N., S. Schaks, K. Dimova, S. Kalkhof, C. Ihling, K. Kölbel, U. Ashery, J. Rhee, N. Brose, A. Sinz, and O. Jahn. 2012. Nonconserved $\mathrm{Ca}^{2+} /$ calmodulin binding sites in Munc13s differentially control synaptic short-term plasticity. Mol. Cell. Biol. 32:4628-4641. http:// dx.doi.org/10.1128/MCB.00933-12

Lipstein, N., T. Sakaba, B.H. Cooper, K.-H. Lin, N. Strenzke, U. Ashery, J.-S. Rhee, H. Taschenberger, E. Neher, and N. Brose. 2013. Dynamic control of synaptic vesicle replenishment and short-term plasticity by $\mathrm{Ca}^{2+}$-calmodulin-Munc13-1 signaling. Neuron. 79:82-96. http://dx.doi.org/10.1016/j.neuron.2013.05.011

Liu, H., H. Bai, E. Hui, L. Yang, C.S. Evans, Z. Wang, S.E. Kwon, and E.R. Chapman. 2014. Synaptotagmin 7 functions as a $\mathrm{Ca}^{2+}$-sensor for synaptic vesicle replenishment. eLife. 3:e01524. http://dx.doi.org/ 10.7554/eLife.01524

Llinás, R., T.L. McGuinness, C.S. Leonard, M. Sugimori, and P. Greengard. 1985. Intraterminal injection of synapsin I or calcium/ calmodulin-dependent protein kinase II alters neurotransmitter release at the squid giant synapse. Proc. Natl. Acad. Sci. USA. 82:30353039. http://dx.doi.org/10.1073/pnas.82.9.3035

Mandell, J.W., E. Townes-Anderson, A.J. Czernik, R. Cameron, P. Greengard, and P. De Camilli. 1990. Synapsins in the vertebrate retina: absence from ribbon synapses and heterogeneous distribution among conventional synapses. Neuron. 5:19-33. http:// dx.doi.org/10.1016/0896-6273(90)90030-J

Massey, S.C., D.A. Redburn, and M.L. Crawford. 1983. The effects of 2-amino-4-phosphonobutyric acid (APB) on the ERG and ganglion cell discharge of rabbit retina. Vision Res. 23:1607-1613. http:// dx.doi.org/10.1016/0042-6989(83)90174-8

Mennerick, S., and G. Matthews. 1996. Ultrafast exocytosis elicited by calcium current in synaptic terminals of retinal bipolar neurons. Neuron. 17:1241-1249. http://dx.doi.org/10.1016/ S0896-6273(00)80254-8

Mizoguchi, A., Y. Yano, H. Hamaguchi, H. Yanagida, C. Ide, A. Zahraoui, H. Shirataki, T. Sasaki, and Y. Takai. 1994. Localization of Rabphilin-3A on the synaptic vesicle. Biochem. Biophys. Res. Commun. 202:1235-1243. http://dx.doi.org/10.1006/bbrc.1994.2063

Nayak, A.S., C.I. Moore, and M.D. Browning. 1996. $\mathrm{Ca}^{2+} / \mathrm{calmodu-}$ lin-dependent protein kinase II phosphorylation of the presynaptic protein synapsin I is persistently increased during long-term potentiation. Proc. Natl. Acad. Sci. USA. 93:15451-15456. http:// dx.doi.org/10.1073/pnas.93.26.15451

Neher, E. 2010. What is rate-limiting during sustained synaptic activity: vesicle supply or the availability of release sites. Front. Synaptic Neurosci. 2:144. http://dx.doi.org/10.3389/fnsyn.2010.00144

Nichols, R.A., T.S. Sihra, A.J. Czernik, A.C. Nairn, and P. Greengard. 1990. Calcium/calmodulin-dependent protein kinase II increases glutamate and noradrenaline release from synaptosomes. Nature. 343:647-651. http://dx.doi.org/10.1038/343647a0

Nielander, H.B., F. Onofri, F. Valtorta, G. Schiavo, C. Montecucco, P. Greengard, and F. Benfenati. 1995. Phosphorylation of VAMP/ synaptobrevin in synaptic vesicles by endogenous protein kinases. J. Neurochem. 65:1712-1720. http://dx.doi.org/10.1046/ j.1471-4159.1995.65041712.x

Nonet, M.L., J.E. Staunton, M.P. Kilgard, T. Fergestad, E. Hartwieg, H.R. Horvitz, E.M. Jorgensen, and B.J. Meyer. 1997. Caenorhabditis elegans rab-3 mutant synapses exhibit impaired function and are partially depleted of vesicles. J. Neurosci. 17:8061-8073.

Oesch, N.W., and J.S. Diamond. 2011. Ribbon synapses compute temporal contrast and encode luminance in retinal rod bipolar cells. Nat. Neurosci. 14:1555-1561. http://dx.doi.org/10.1038/ nn.2945

Ohyama, A., K. Hosaka, Y. Komiya, K. Akagawa, E. Yamauchi, H. Taniguchi, N. Sasagawa, K. Kumakura, S. Mochida, T. Yamauchi, and M. Igarashi. 2002. Regulation of exocytosis through $\mathrm{Ca}^{2+} /$ ATP-dependent binding of autophosphorylated $\mathrm{Ca}^{2+} /$ calmodulinactivated protein kinase II to syntaxin 1A. J. Neurosci. 22:3342-3351.

Paillart, C., J. Li, G. Matthews, and P. Sterling. 2003. Endocytosis and vesicle recycling at a ribbon synapse. J. Neurosci. 23:4092-4099.

Palmer, M.J., C. Hull, J. Vigh, and H. von Gersdorff. 2003. Synaptic cleft acidification and modulation of short-term depression by exocytosed protons in retinal bipolar cells. J. Neurosci. 23:11332-11341.

Pang, Z.P., P. Cao, W. Xu, and T.C. Südhof. 2010. Calmodulin controls synaptic strength via presynaptic activation of calmodulin kinase II. J. Neurosci. 30:4132-4142. http://dx.doi.org/10.1523/ JNEUROSCI.3129-09.2010

Rabl, K., L. Cadetti, and W.B. Thoreson. 2005. Kinetics of exocytosis is faster in cones than in rods. J. Neurosci. 25:4633-4640. http:// dx.doi.org/10.1523/JNEUROSCI.4298-04.2005

Rabl, K., L. Cadetti, and W.B. Thoreson. 2006. Paired-pulse depression at photoreceptor synapses. J. Neurosci. 26:2555-2563. http:// dx.doi.org/10.1523/JNEUROSCI.3667-05.2006

Rea, R., J. Li, A. Dharia, E.S. Levitan, P. Sterling, and R.H. Kramer. 2004. Streamlined synaptic vesicle cycle in cone photoreceptor terminals. Neuron. 41:755-766. http://dx.doi.org/10.1016/S08966273(04)00088-1

Regus-Leidig, H., C. Ott, M. Löhner, J. Atorf, M. Fuchs, T. Sedmak, J. Kremers, A. Fejtová, E.D. Gundelfinger, and J.H. Brandstätter. 2013. Identification and immunocytochemical characterization of Piccolino, a novel Piccolo splice variant selectively expressed at sensory ribbon synapses of the eye and ear. PLoS ONE. 8:e70373. http://dx.doi.org/10.1371/journal.pone.0070373

Risinger, C., and M.K. Bennett. 1999. Differential phosphorylation of syntaxin and synaptosome-associated protein of $25 \mathrm{kDa}$ (SNAP-25) isoforms. J. Neurochem. 72:614-624. http://dx.doi.org/10.1046/ j.1471-4159.1999.0720614.x

Rodríguez-Castañeda, F., M. Maestre-Martínez, N. Coudevylle, K. Dimova, H. Junge, N. Lipstein, D. Lee, S. Becker, N. Brose, O. Jahn, et al. 2010. Modular architecture of Munc13/calmodulin complexes: dual regulation by $\mathrm{Ca}^{2+}$ and possible function in short-term synaptic plasticity. EMBO J. 29:680-691. http://dx.doi .org/10.1038/emboj.2009.373

Rubenstein, J.L., P. Greengard, and A.J. Czernik. 1993. Calciumdependent serine phosphorylation of synaptophysin. Synapse. 13:161-172. http://dx.doi.org/10.1002/syn.890130207

Sakaba, T., and E. Neher. 2001. Calmodulin mediates rapid recruitment of fast-releasing synaptic vesicles at a calyx-type synapse. Neuron. 32:1119-1131. http://dx.doi.org/10.1016/S0896-6273 (01) 00543-8

Sakaba, T., R. Schneggenburger, and E. Neher. 2002. Estimation of quantal parameters at the calyx of Held synapse. Neurosci. Res. 44:343-356. http://dx.doi.org/10.1016/S0168-0102(02)00174-8

Schikorski, T., and C.F. Stevens. 1997. Quantitative ultrastructural analysis of hippocampal excitatory synapses. J. Neurosci. 17:5858-5867.

Schlüter, O.M., F. Schmitz, R. Jahn, C. Rosenmund, and T.C. Südhof. 2004. A complete genetic analysis of neuronal Rab3 function. J. Neurosci. 24:6629-6637. http://dx.doi.org/10.1523/ JNEUROSCI.1610-04.2004

Schlüter, O.M., J. Basu, T.C. Südhof, and C. Rosenmund. 2006. Rab3 superprimes synaptic vesicles for release: implications for short-term synaptic plasticity. J. Neurosci. 26:1239-1246. http://dx.doi.org/ 10.1523/JNEUROSCI.3553-05.2006

Schnapf, J.L., and D.R. Copenhagen. 1982. Differences in the kinetics of rod and cone synaptic transmission. Nature. 296:862-864. http:/ / dx.doi.org/10.1038/296862a0 
Schneggenburger, R., T. Sakaba, and E. Neher. 2002. Vesicle pools and short-term synaptic depression: lessons from a large synapse. Trends Neurosci. 25:206-212. http://dx.doi.org/10.1016/ S0166-2236(02) 02139-2

Sheng, Z., S.-Y. Choi, A. Dharia, J. Li, P. Sterling, and R.H. Kramer. 2007. Synaptic $\mathrm{Ca}^{2+}$ in darkness is lower in rods than cones, causing slower tonic release of vesicles. J. Neurosci. 27:5033-5042. http:// dx.doi.org/10.1523/JNEUROSCI.5386-06.2007

Shtrahman, M., C. Yeung, D.W. Nauen, G.Q. Bi, and X.-L. Wu. 2005. Probing vesicle dynamics in single hippocampal synapses. Biophys. J. 89:3615-3627. http://dx.doi.org/10.1529/biophysj.105.059295

Singer, J.H., and J.S. Diamond. 2006. Vesicle depletion and synaptic depression at a mammalian ribbon synapse. J. Neurophysiol. 95:3191-3198. http://dx.doi.org/10.1152/jn.01309.2005

Snellman, J., B. Mehta, N. Babai, T.M. Bartoletti, W. Akmentin, A. Francis, G. Matthews, W. Thoreson, and D. Zenisek. 2011. Acute destruction of the synaptic ribbon reveals a role for the ribbon in vesicle priming. Nat. Neurosci. 14:1135-1141. http://dx.doi.org/10.1038/ nn. 2870

Stevens, C.F., and J.F. Wesseling. 1998. Activity-dependent modulation of the rate at which synaptic vesicles become available to undergo exocytosis. Neuron. 21:415-424. http://dx.doi.org/10.1016/ S0896-6273(00) 80550-4

Sun, J., P. Bronk, X. Liu, W. Han, and T.C. Südhof. 2006. Synapsins regulate use-dependent synaptic plasticity in the calyx of Held by a $\mathrm{Ca}^{2+}$ /calmodulin-dependent pathway. Proc. Natl. Acad. Sci. USA. 103:2880-2885. http://dx.doi.org/10.1073/pnas.0511300103

Sun, T., X.-S. Wu, J. Xu, B.D. McNeil, Z.P. Pang, W. Yang, L. Bai, S. Qadri, J.D. Molkentin, D.T. Yue, and L.-G. Wu. 2010. The role of calcium/calmodulin-activated calcineurin in rapid and slow endocytosis at central synapses. J. Neurosci. 30:11838-11847. http:// dx.doi.org/10.1523/JNEUROSCI.1481-10.2010

Thoreson, W.B., K. Rabl, E. Townes-Anderson, and R. Heidelberger. 2004. A highly $\mathrm{Ca}^{2+}$-sensitive pool of vesicles contributes to linearity at the rod photoreceptor ribbon synapse. Neuron. 42:595-605. http://dx.doi.org/10.1016/S0896-6273(04)00254-5

Tian, M., C.S. Xu, R. Montpetit, and R.H. Kramer. 2012. Rab3A mediates vesicle delivery at photoreceptor ribbon synapses. J. Neurosci. 32: 6931-6936. http://dx.doi.org/10.1523/JNEUROSCI.0265-12.2012

Uthaiah, R.C., and A.J. Hudspeth. 2010. Molecular anatomy of the hair cell's ribbon synapse. J. Neurosci. 30:12387-12399. http:// dx.doi.org/10.1523/JNEUROSCI.1014-10.2010

van Hateren, J.H. 1997. Processing of natural time series of intensities by the visual system of the blowfly. Vision Res. 37:3407-3416. http://dx.doi.org/10.1016/S0042-6989(97)00105-3

Van Hook, M.J., and W.B. Thoreson. 2012. Rapid synaptic vesicle endocytosis in cone photoreceptors of salamander retina. J. Neurosci. 32:18112-18123. http://dx.doi.org/10.1523/JNEUROSCI $.1764-12.2012$
Van Hook, M.J., and W.B. Thoreson. 2013. Simultaneous wholecell recordings from photoreceptors and second-order neurons in an amphibian retinal slice preparation. J. Vis. Exp. 76:e50007. http://dx.doi.org/10.3791/50007

Verona, M., S. Zanotti, T. Schäfer, G. Racagni, and M. Popoli. 2000. Changes of synaptotagmin interaction with t-SNARE proteins in vitro after calcium/calmodulin-dependent phosphorylation. J. Neurochem. 74:209-221. http://dx.doi.org/10.1046/j.1471-4159 .2000.0740209.x

Von Kriegstein, K., F. Schmitz, E. Link, and T.C. Südhof. 1999. Distribution of synaptic vesicle proteins in the mammalian retina identifies obligatory and facultative components of ribbon synapses. Eur. J. Neurosci. 11:1335-1348. http://dx.doi.org/ 10.1046/j.1460-9568.1999.00542.x

Wang, L.Y., and L.K. Kaczmarek. 1998. High-frequency firing helps replenish the readily releasable pool of synaptic vesicles. Nature. 394:384-388. http://dx.doi.org/10.1038/28645

Wesseling, J.F., and D.C. Lo. 2002. Limit on the role of activity in controlling the release-ready supply of synaptic vesicles. J. Neurosci. 22:9708-9720.

Wu, L.-G., T.A. Ryan, and L. Lagnado. 2007. Modes of vesicle retrieval at ribbon synapses, calyx-type synapses, and small central synapses. J. Neurosci. 27:11793-11802. http://dx.doi.org/ 10.1523/JNEUROSCI.3471-07.2007

Wu, X.-S., B.D. McNeil, J. Xu, J. Fan, L. Xue, E. Melicoff, R. Adachi, L. Bai, and L.-G. Wu. 2009. $\mathrm{Ca}^{2+}$ and calmodulin initiate al forms of endocytosis during depolarization at a nerve terminal. Nat. Neurosci. 12:1003-1010. (published erratum appears in Nat. Neurosci. 2010. 13:649) http://dx.doi.org/10.1038/nn.2355

Xu, X., and C. Karwoski. 1995. Current source density analysis of the electroretinographic d wave of frog retina. J. Neurophysiol. 73:2459-2469.

Yao, L., and T. Sakaba. 2012. Activity-dependent modulation of endocytosis by calmodulin at a large central synapse. Proc. Natl. Acad. Sci. USA. 109:291-296. http://dx.doi.org/10.1073/pnas .1100608109

Zampighi, G.A., C. Schietroma, L.M. Zampighi, M. Woodruff, E.M. Wright, and N.C. Brecha. 2011. Conical tomography of a ribbon synapse: structural evidence for vesicle fusion. PLoS ONE. 6:e16944. http://dx.doi.org/10.1371/journal.pone .0016944

Zhang, J., and S.M. Wu. 2005. Physiological properties of rod photoreceptor electrical coupling in the tiger salamander retina. J. Physiol. 564:849-862. http://dx.doi.org/10.1113/jphysiol.2005.082859

Zikich, D., A. Mezer, F. Varoqueaux, A. Sheinin, H.J. Junge, E. Nachliel, R. Melamed, N. Brose, M. Gutman, and U. Ashery. 2008. Vesicle priming and recruitment by ubMunc13-2 are differentially regulated by calcium and calmodulin. J. Neurosci. 28:1949-1960. http://dx.doi.org/10.1523/JNEUROSCI.5096-07.2008 
Van Hook et al., http://www.jgp.org/cgi/content/full/jgp.201411229/DC1

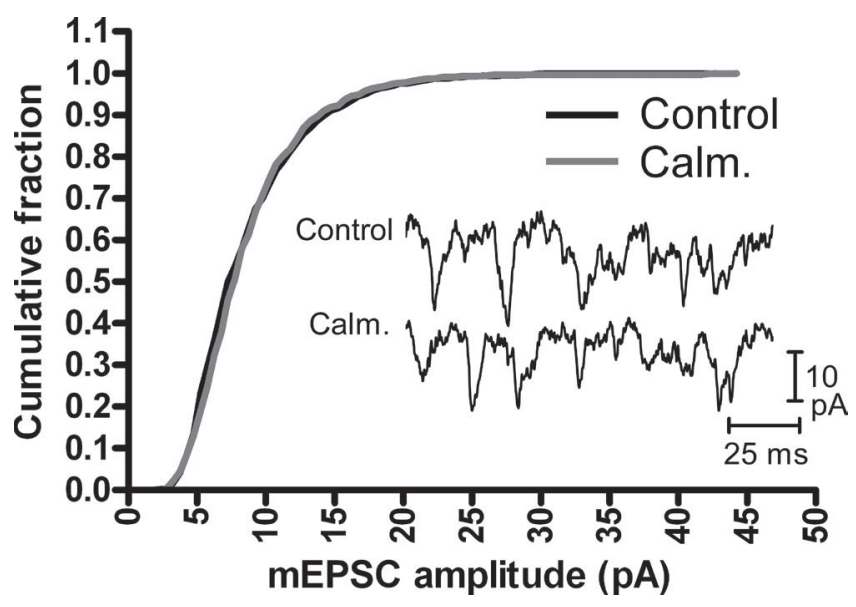

Figure S1. Miniature EPSC amplitude was not affected by calmidazolium. Cumulative frequency distribution of HC mEPSC amplitudes recorded in control conditions and in the presence of calmidazolium (Calm.; $20 \mu \mathrm{M}$ ). (inset) Example traces of mEPSCs from a single HC recorded before (control) and 5 min after application of calmidazolium.
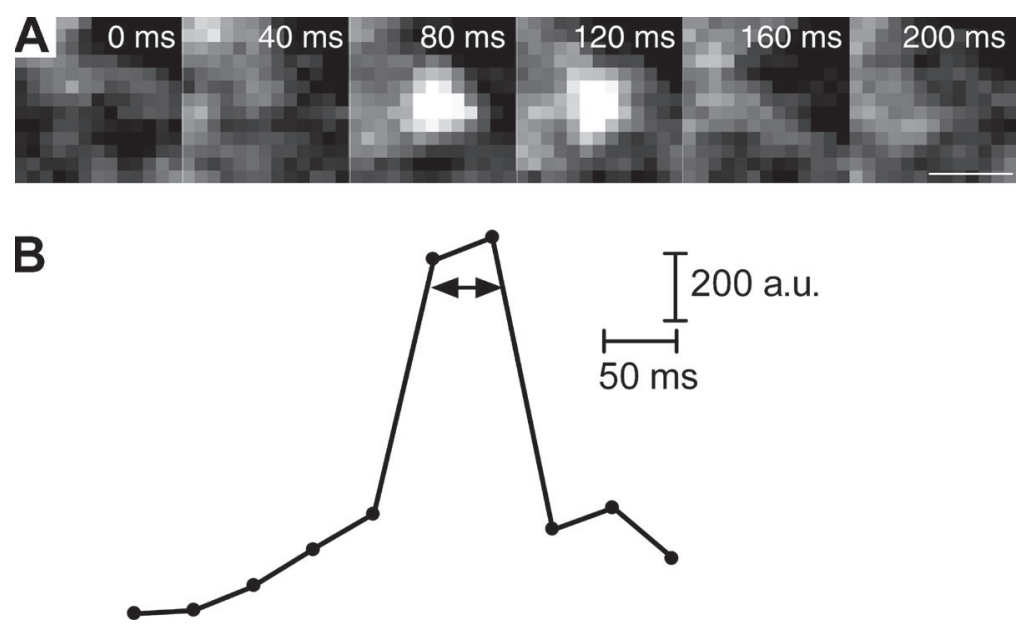

Figure S2. Imaging of single-vesicle fusion events. To test whether the time that vesicles spend at the membrane before fusion might limit the rate of replenishment in cones, we used TIRFM to image membrane approach, docking, and fusion of individual vesicles in isolated cone photoreceptors loaded with a dextran-conjugated, $\mathrm{pH}$-sensitive form of rhodamine (pHrodo). (A) Consecutive images showing the appearance and disappearance of a single pHrodo-loaded synaptic vesicle in a cone terminal. Bar, $500 \mathrm{~nm}$. (B) Change in fluorescence plotted as a function of time. The membrane dwell time, marked with the double arrow, is the interval from the $90 \%$ rise to $10 \%$ decline in pHrodo fluorescence intensity. This was measured as the number of frames in which fluorescence exceeded $90 \%$ of the peak pHrodo fluorescence value. Upon depolarizing stimulation, pHrodo-loaded vesicles entered the thin evanescent field of illumination (length constant $=64 \mathrm{~nm}$; Chen et al., 2013), becoming progressively brighter as they approached the membrane. After spending a brief time near the membrane, vesicle fluorescence declined abruptly as pHrodo was released upon fusion and the fluorescence was quenched by the alkaline $\mathrm{pH}$ (7.8) of the extracellular environment. The membrane dwell times of single vesicles before fusion averaged $46.8 \pm 2.4 \mathrm{~ms}$ ( $n=41$ fusion events), similar to that for vesicles in rods (Chen et al., 2013). The finding that membrane dwell times were substantially shorter than the measured $\tau_{\text {fast }}$ for replenishment $(\sim 800 \mathrm{~ms})$ indicates that they do not limit the rate of replenishment and are thus unlikely to underlie $\mathrm{Ca}^{2+} / \mathrm{CaM}$ acceleration of replenishment. 
A

Baseline

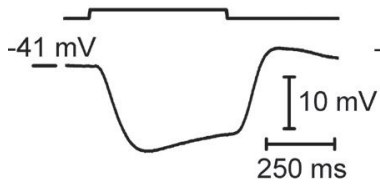

Calm.

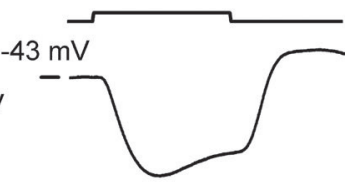

B

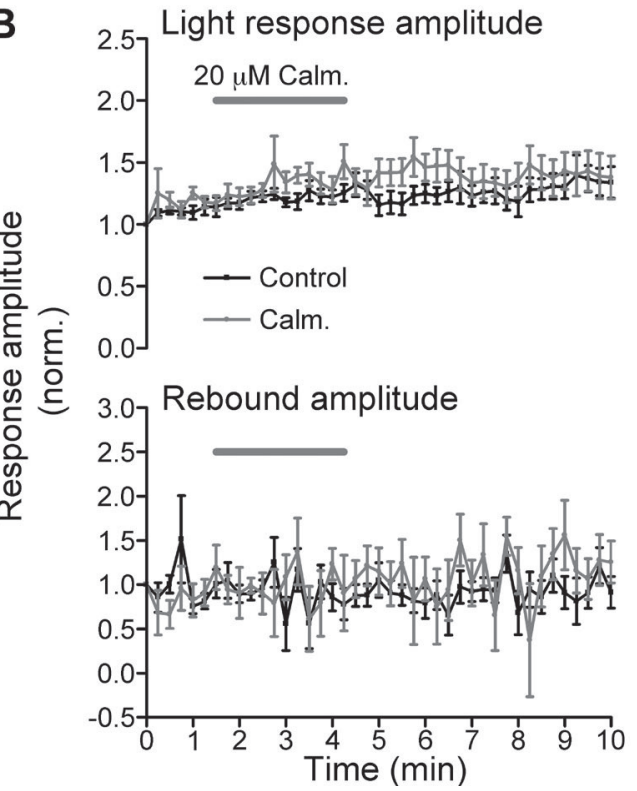

Figure S3. Cone light responses were not affected by calmidazolium. (A) Perforated patch current-clamp recording of responses of a cone to a 500-ms light flash delivered before (left) and during application of $20 \mu \mathrm{M}$ calmidazolium (Calm.; right). (B) Group data. Cones were stimulated with a 500-ms flash of light every $15 \mathrm{~s}$. Although the amplitude of the light-evoked hyperpolarization increased gradually over the course of the recording, it was not affected by calmidazolium when compared with controls. Normalized to the first light response, the amplitude was $1.32 \pm 0.7$ in the presence of $\mathrm{CaM}(n=10)$ and $1.21 \pm 0.05$ when CaM was not added $(n=10 ; \mathrm{P}=0.2)$. Likewise, the amplitude of the depolarization at light offset (rebound) was not significantly different between control and calmidazolium conditions. Normalized to the first response, the amplitude of the rebound was $0.97 \pm 0.18(n=10)$ in the presence of calmidazolium and $0.92 \pm 0.08$ when calmidazolium was not added $(n=10 ; \mathrm{P}=0.8)$. These results suggest that calmidazolium affects the light responses of HCs and Off $\mathrm{BCs}$ by affecting synaptic transmission rather than by affecting cone phototransduction. Mean \pm SEM is shown.
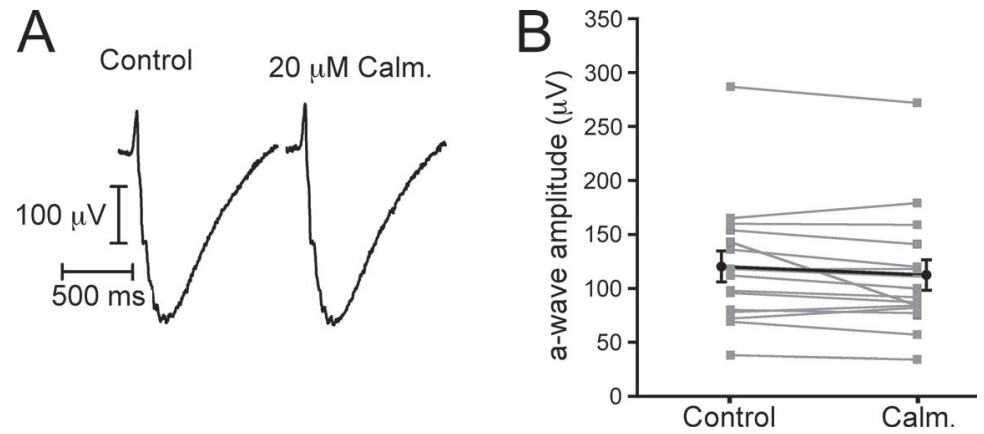

Figure S4. ERG a-wave was not affected by calmidazolium. The population cone light response was measured using intraretinal ERG recordings from salamander eyecups. (A) Example ERG traces from a single eyecup before and after application of $20 \mu \mathrm{M}$ calmidazolium (Calm.). In this intraretinal recording configuration, the a-wave is the positive-going component that is followed by a slower, negative-going b-wave. (B) Population data showing that the a-wave amplitude was not affected by calmidazolium. Control amplitude $=120 \pm$ $14 \mu \mathrm{V}$; calmidazolium amplitude $=112 \pm 14 \mu \mathrm{V}(n=16 ; \mathrm{P}>0.05$, paired $t$ test $)$. Mean \pm SEM is shown.

\section{REFERENCE}

Chen, M., M.J. Van Hook, D. Zenisek, and W.B. Thoreson. 2013. Properties of ribbon and non-ribbon release from rod photoreceptors revealed by visualizing individual synaptic vesicles. J. Neurosci. 33:2071-2086. http://dx.doi.org/10.1523/JNEUROSCI.3426-12.2013 